\title{
FUNDAMENTAL AND NON-FUNDAMENTAL EQUILIBRIA IN THE FOREIGN EXCHANGE MARKET. A BEHAVIOURAL FINANCE FRAMEWORK
}

\author{
PAUL DE GRAUWE \\ ROBERTO DIECI \\ MARIANNA GRIMALDI
}

CESIFO WORKING PAPER NO. 1431

CATEGORY 6: MONETARY POLICY AND INTERNATIONAL FINANCE MARCH 2005

Presented AT CESifo AREa CONFERENCE ON

MaCro, MONEy \& InTERnATIONAL FinANCE, FEBRUARY 2005

\footnotetext{
An electronic version of the paper may be downloaded

- from the SSRN website: http://SSRN.com/abstract $=692021$

- from the CESifo website: www.CESifo.de
} 


\title{
FUNDAMENTAL AND NON-FUNDAMENTAL EQUILIBRIA IN THE FOREIGN EXCHANGE MARKET. A BEHAVIOURAL FINANCE FRAMEWORK
}

\begin{abstract}
We develop a simple model of the exchange rate in which agents optimize their portfolio and use different forecasting rules. They check the profitability of these rules ex post and select the more profitable one. This model produces two kinds of equilibria, a fundamental and a bubble one. In a stochastic environment the model generates a complex dynamics in which bubbles and crashes occur at unpredictable moments. We contrast these "behavioural" bubbles with "rational" bubbles.
\end{abstract}

JEL Code: F31, F41, G10.

Keywords: exchange rate, bounded rationality, heterogeneous agents, bubbles and crashes, complex dynamics, basins of attraction.

\author{
Paul De Grauwe \\ University of Leuven \\ Naamsestraat 69 \\ 3000 Leuven \\ Belgium \\ paul.degrauwe@econ.kuleuven.be
}

\author{
Roberto Dieci \\ University of Bologna \\ Economic Faculty - Rimini \\ Via Angherà, 22 \\ Rimini \\ Italy \\ rdieci@rimini.unibo.it
}

\author{
Marianna Grimaldi \\ Research Department \\ Sveriges Riksbank \\ 10337 Stockholm \\ Sweden \\ marianna.grimaldi@riskbank.se
}

Paper presented at the CESifo Area Conference Macro, Money and International Finance, 2526 February 2005. We are very grateful for useful comments to our discussant, Ronnie MacDonald and to the conference participants. 


\section{Introduction}

Exchange rate modelling is still dominated by the rational-expectations-efficientmarket (REEM) paradigm. One of the implications of the REEM paradigm is that the exchange rate can only change if there is news in the underlying fundamentals. The accumulated empirical evidence, however, suggests that this paradigm cannot be maintained. There are too many empirical anomalies that contradict the predictions that can be derived from this model.

The first and foremost empirical puzzle has been called the "disconnect" puzzle, i.e. the exchange rate appears to be disconnected from its underlying fundamentals most of the time. Goodhart (1989), Goodhart and Figlioli (1991) and more recently Faust et al. (2002) found that most of the changes in the exchange rates occur when there is no observable news in the fundamental economic variables.

Other empirical anomalies have been uncovered over the years. One is the puzzle of "excess volatility" of the exchange rate, i.e. the volatility of the exchange rate by far exceeds the volatility of the underlying economic variables (Baxter and Stockman (1989) and Flood and Rose (1995)).

Another puzzle is that the distribution of the exchange rate returns is not normal. Most of the empirical findings document that the exchange rate returns have fat tails and excess kurtosis (see de Vries(2001), Lux T. (1998), Lux and Marchesi (1999). This evidence is difficult to rationalise in existing exchange rate models, since there is little evidence of fat tails in the fundamental variables that drive the exchange rate in these models.

Implicit in the REEM model is the view that agents (at least some of them) understand the structure of the underlying model and that they use this information to make predictions. In a way this is an extraordinary assumption. It implies that individual agents can store and process all available information, including the knowledge of how the world functions, in their individual brains. It seems quite unreasonable to assume that an individual brain is large and complex enough to master the full complexity of the outside world. Such an extraordinary assumption could still be maintained if it led to powerful empirical predictions about financial markets. The truth is that it does not.

In this paper we will take the view that agents have a limited capacity for understanding and processing the complex information. In order to cope with the complexity of the world agents use relatively simple behavioral rules. However, they are not stupid. They compare the rule they currently use to alternative rules and decide to switch to the alternative if it turns out that this is more profitable. In other words they check the "fitness" of these rules. In this sense these agents are boundedly rational. Their strategy of trial and error is the best possible response to a highly uncertain environment

This approach is also very much influenced by the literature of "behavioural finance" (Tversky and Kahneman(1981), Thaler(1994), Shleifer(2000), Kahne$\operatorname{man}(2002))$.

We will show that in a model with boundedly rational agents two types of regimes exist, a fundamental and a bubble one. Both of them will be shown 
to be fixed point solutions of the underlying deterministic model. We will then analyse the nature of these "bubble equilibria" and the conditions in which they are working as attactors. The model will be formulated in the context of the exchange market ${ }^{1}$.

\section{The model}

In this section we develop a simple exchange rate model. As will be seen, the model can be interpreted more generally as a model describing any risky asset price. The model consists of three building blocks. First, utility maximising agents select their optimal portfolio using a mean-variance utility framework. Second, these agents make forecasts about the future exchange rate based on simple but different rules. In this second building block we introduce concepts borrowed from the behavioural finance literature. Third, agents evaluate these rules ex-post by comparing their risk-adjusted profitability. Thus, the third building block relies on an evolutionary economics.

\subsection{The optimal portfolio}

We assume agents of different types $i$ depending on their beliefs about the future exchange rate. Each agent can invest in two assets, a domestic asset and foreign assets. The agents' expected utility can be represented by the following equation:

$$
U\left(W_{t+1}^{i}\right)=E_{t}^{i}\left(W_{t+1}^{i}\right)-\frac{1}{2} \mu V_{t}^{i}\left(W_{t+1}^{i}\right)
$$

where $W_{t+1}^{i}$ is the wealth of agent of type $i$ at time $t+1, E_{t}^{i}$ is the expectation operator, $\mu$ is the coefficient of risk aversion and $V_{t}^{i}\left(W_{t+1}^{i}\right)$ represents the conditional variance of wealth of agent $i$. The wealth is specified as follows:

$$
W_{t+1}^{i}=\left(1+r^{*}\right) s_{t+1} d_{i, t}+(1+r)\left(W_{t}^{i}-s_{t} d_{i, t}\right)
$$

where $r$ and $r^{*}$ are respectively the domestic and the foreign interest rates (which are known with certainty), $s_{t+1}$ is the exchange rate at time $t+1, d_{i, t}$ represents the holdings of the foreign assets by agent of type $i$ at time $t$. Thus, the first term on the right-hand side of (2) represents the value of the foreign portfolio expressed in domestic currency at time $t+1$ while the second term represents the value of the domestic portfolio at time $t+1^{2}$.

Substituiting equation (2) into (1) and maximising the utility with respect to $d_{i, t}$ allows us to derive the standard optimal holding of foreign assets by agents

\footnotetext{
${ }^{1}$ Its basic structure can also be applied to other asset markets.

${ }^{2}$ The model could be interpreted as an asset pricing model with one risky asset (e.g. shares) and a risk free asset. Equation (2) would then be written as

$W_{t+1}^{i}=\left(s_{t+1}+y_{t+1}\right) d_{i, t}+(1+r)\left(W_{t}^{i}-s_{t} d_{i, t}\right)$ where $s_{t+1}$ is the price of the share in $t+1$ and $y_{t+1}$ is the dividend per share in $t+1$.
} 
of type $i^{3}:$

$$
d_{i, t}=\frac{\left(1+r^{*}\right) E_{t}^{i}\left(s_{t+1}\right)-(1+r) s_{t}}{\mu \sigma_{i, t}^{2}}
$$

where $\sigma_{i, t}^{2}=\left(1+r^{*}\right)^{2} V_{t}^{i}\left(s_{t+1}\right)$. The optimal holding of the foreign asset depends on the expected excess return (corrected for risk) of the foreign asset. The market demand for foreign assets at time $t$ is the sum of the individual demands, i.e.:

$$
\sum_{i=1}^{N} n_{i, t} d_{i, t}=D_{t}
$$

where $n_{i, t}$ is the number of agents of type $i$.

Market equilibrium implies that the market demand is equal to the market supply $Z_{t}$ which we assume to be exogenous ${ }^{4}$. Thus,

$$
Z_{t}=D_{t}
$$

Substituting the optimal holdings (3) into the market demand (4) and then into the market equilibrium equation (5) and solving for the exchange rate $s_{t}$ yields the market clearing exchange rate:

$$
s_{t}=\left(\frac{1+r^{*}}{1+r}\right) \frac{1}{\sum_{i=1}^{N} \frac{w_{i, t}}{\sigma_{i, t}^{2}}}\left[\sum_{i=1}^{N} w_{i, t} \frac{E_{t}^{i}\left(s_{t+1}\right)}{\sigma_{i, t}^{2}}-\Omega_{t} Z_{t}\right]
$$

where $w_{i, t}=\frac{n_{i, t}}{\sum_{i=1}^{N} n_{i, t}}$ is the weight (share) of agent $i$, and $\Omega_{t}=\frac{\mu}{\left(1+r^{*}\right) \sum_{i=1}^{N} n_{i, t}}$.

Thus the market clearing exchange rate is determined by the forecasts of the agents, $E_{t}^{i}$, about the future exchange rate.

Note also that the forecasts are weighted by their respective variances $\sigma_{i, t}^{2}$. When agent's $i$ forecasts have a high variance the weight of this agent in the determination of the market exchange rate is reduced.

\subsection{The forecasting rules}

We now specify how agents form their expectations of the future exchange rate and how they evaluate the risk of their portfolio.

\footnotetext{
${ }^{3}$ If the model is interpreted as an asset pricing model of one risky asset (shares) and a risk free asset, the corresponding optimal holding of the risky asset becomes

$$
d_{i, t}=\frac{E_{t}^{i}\left(s_{t+1}+y_{t+1}\right)-(1+r) s_{t}}{\mu \sigma_{i, t}^{2}}
$$

where $s_{t+1}$ and $y_{t+1}$ are the price and the dividend at $t+1$, respectively, and $\sigma_{i, t}^{2} \equiv$ $V_{t}^{i}\left(s_{t+1}+y_{t+1}\right)$.

${ }^{4}$ The market supply is determined by the net current account and by the sales or purchases of foreign exchange of the central bank. We assume both to be exogenous here.
} 
We start with an analysis of the rules agents use in forecasting the exchange rate. We take the view that individual agents are overwhelmed by the complexity of the informational environment, and therefore use simple rules to make forecasts. Here we describe these rules. In the next section we discuss how agents select the rules.

We assume that two types of forecasting rules are used. One is called a "fundamentalist" rule, the other a "technical trading" rule ${ }^{5}$. The agents using a fundamentalist rule, the "fundamentalists", base their forecast on a comparison between the market and the fundamental exchange rate, i.e. they forecast the market rate to return to the fundamental rate in the future. In this sense they use a negative feedback rule that introduces a mean reverting dynamics in the exchange rate. The speed with which the market exchange rate returns to the fundamental is assumed to be determined by the speed of adjustment in the goods market which is assumed to be in the information set of the fundamentalists (together with the fundamental exchange rate itself). Thus, the forecasting rule for the fundamentalists is :

$$
E_{t}^{f}\left(\Delta s_{t+1}\right)=-\psi\left(s_{t-1}-s_{t-1}^{*}\right)
$$

where $s_{t}^{*}$ is the fundamental exchange rate at time $t$, which is assumed to follow a random walk and $0<\psi<1$. We assume that the fundamental exchange rate is exogenous.

The timing of the forecasts is important. When fundamentalists forecast the future exchange rate they use publicly available information up to period $t-1$. This implies that fundamentalists make their forecasts before the market clearing exchange rate $s_{t}$ has been revealed to them ${ }^{6}$. This assumption is in the logic of the model used here in which agents do not know the full model structure. As a result, they cannot compute the market clearing exchange rate of time $t$ that will be the result of their decisions made in period $t^{7}$.

The timing assumption underlying the agents' forecasts in (7) allows us to derive the market clearing exchange rate in (6) as a unique price for which demand equals supply (see Brock and Hommes (1998)). An issue that arises here is how this timing assumption can be made consistent with the optimisation process described in the previous section. There we assumed that when computing their optimal holdings of foreign assets in period $t$, agents have information about the exchange rate in period $t$. The inconsistency is only apparent. The optimal holdings derived in equation (3) can be interpreted as a Marshalian demand curve in which an auctioneer announces a price, $s_{t}$. Agents then decide on their optimal holdings conditioned on this announced price. The auctioneer then collects the bids and offers, and computes the market clearing price. The

\footnotetext{
${ }^{5}$ The idea of distinguishing between fundamentalist and technical traders rules was first introduced by Frankel and Froot(1987).

${ }^{6}$ When we consider agents' expectations, at time $t$, of the exchange rate change we define $E_{i, t}\left(\Delta s_{t+1}\right) \equiv E_{i, t}\left(s_{t+1}-s_{t-1}\right), i=f, c$.

${ }^{7}$ In an environment with fully and perfectly informed agents, agents know the underlying model and are capable of making such calculations. As a result, in such models agents use information about the exchange rate at time $t$.
} 
latter is not in the information set of the agents when they make their forecasts for the exchange rate in period $t+1$.

The chartists are assumed to follow a positive feedback rule, i.e. they extrapolate past movements of the exchange rate into the future. The chartists' forecast is written as:

$$
E_{c, t}\left(\Delta s_{t+1}\right)=\beta \sum_{h=1}^{H} \rho_{h} \Delta s_{t-h}
$$

Here $E_{c, t}$ is the forecast made by the chartists using information up to time $t-1$, and $\beta$ is the coefficient expressing the degree with which chartists extrapolate the past change in the exchange rate; we assume that $0<\beta<1$ to ensure dynamic stability. Thus, the chartists compute a moving average of the past exchange rate changes and they extrapolate these changes into the future exchange rate change. We set $\rho_{h}=\left[(1-\rho) \rho^{h-1}\right] /\left(1-\rho^{H}\right)$, where $1-\rho^{H}=\sum_{h=1}^{H}(1-\rho) \rho^{h-1}$. Thus we assume an exponential decay in the weights given to the past exchange rate changes. In our base simulation we assume a finite number of lags $(H=5)$. Note that in the limiting case $H \rightarrow \infty$, the assumption of exponential decay allows us to rewrite equation (8) as

$$
E_{c, t}\left(\Delta s_{t+1}\right)=\rho E_{c, t-1}\left(\Delta s_{t}\right)+(1-\rho) \beta \Delta s_{t-1}
$$

Thus, technical traders take into account information concerning the fundamental exchange rate indirectly, i.e. through the exchange rate itself. In addition, technical rules can be interpreted as rules that attempt to detect "market sentiments". In this sense the technical trader rules can be seen as reflecting herding behaviour ${ }^{8}$. Note that the same assumption about the timing of the information set is used here as in the case of fundamentalist forecasting.

We now analyse how fundamentalists and technical traders evaluate the risk of their portfolio. The risk is measured by the variance terms in equation (6), which we define as the weighted average of the squared (one period ahead) forecasting errors made by technical traders and fundamentalists, respectively. Thus we assume $\sigma_{i, t}^{2}=\left(1+r^{*}\right)^{2} V_{t}^{i}\left(s_{t+1}\right)$ where

$$
V_{t}^{i}\left(s_{t+1}\right)=\sum_{k=1}^{K} \theta_{k}\left[E_{t-k-1}^{i}\left(s_{t-k}\right)-s_{t-k}\right]^{2}
$$

and where $\theta_{k}=\theta(1-\theta)^{k-1} /\left(\sum_{k=1}^{K} \theta(1-\theta)^{k-1}\right)$ are geometrically declining weights $(0<\theta<1), K$ is a finite number of lags, and $i=f, c$. Note that in the limit when $K \rightarrow \infty$, eq. (10) can be rewritten in the recurrent form

$$
V_{t}^{i}\left(s_{t+1}\right)=\theta\left[E_{t-2}^{i}\left(s_{t-1}\right)-s_{t-1}\right]^{2}+(1-\theta) V_{t-1}^{i}\left(s_{t}\right)
$$

${ }^{8}$ There is a large literature on the use of technical analysis. This literature makes clear that technical trading is widely used in the foreign exchange markets. See Cheung and Chinn(1989), Taylor and Allen(1992), Cheung et al(1999), Mentkhoff(1997) and (1998). 


\subsection{Fitness of the rules}

The next step in our analysis is to specify how agents evaluate the fitness of these two forecasting rules. The general idea that we will follow is that agents use one of the two rules, compare their (risk adjusted) profitability ex post and then decide whether to keep the rule or switch to the other one. Thus, our model is in the logic of evolutionary dynamics, in which simple decision rules are selected. These rules will continue to be followed if they pass some "fitness" test (profitability test). Another way to interpret this is as follows. When great uncertainty exists about how the complex world functions, agents use a trial and error strategy. They try a particular forecasting rule until they find out that other rules work better. Such a trial and error strategy is the best strategy agents can use when cannot understand the full complexity of the underlying model.

In order to implement this idea we use an approach proposed by Brock and Hommes(1997) which consists in making the weights of the forecasting rules a function of the relative profitability of these rules, i.e. ${ }^{9}$ :

$$
\begin{gathered}
w_{c, t}=\frac{\exp \left[\gamma \pi_{c, t}^{\prime}\right]}{\exp \left[\gamma \pi_{c, t}^{\prime}\right]+\exp \left[\gamma \pi_{f, t}^{\prime}\right]} \\
w_{f, t}=\frac{\exp \left[\gamma \pi_{f, t}^{\prime}\right]}{\exp \left[\gamma \pi_{c, t}^{\prime}\right]+\exp \left[\gamma \pi_{f, t}^{\prime}\right]}=1-w_{c, t}
\end{gathered}
$$

where $\pi_{c, t}^{\prime}$ and $\pi_{f, t}^{\prime}$ are the risk adjusted net profits computed by technical traders and fundamentalists who forecast the exchange rate in period $t$ using information up to $t-1$, i.e. $\pi_{c, t}^{\prime}=\pi_{c, t}-\mu \sigma_{c, t}^{2}$ and $\pi_{f, t}^{\prime}=\pi_{f, t}-\mu \sigma_{f, t}^{2}$, while $\pi_{c, t}$ and $\pi_{f, t}$ are the net profits, to be defined later.

Equations (12) and (13) can be interpreted as switching rules. When the risk adjusted profits of the technical traders' rule increases relative to the risk adjusted net profits of the fundamentalists rule, then the share of agents who switches and use technical trader rules in period $t$ increases, and vice versa. This parameter $\gamma$ measures the intensity with which the technical traders and fundamentalists revise their forecasting rules. With an increasing $\gamma$ agents react strongly to the relative profitability of the rules. In the limit when $\gamma$ goes to infinity all agents choose the forecasting rule which proves to be more profitable. When $\gamma$ is equal to zero agents are insensitive to the relative profitability of the rules. In the latter case the fraction of technical traders and fundamentalists is constant and equal to 0.5. Thus, $\gamma$ is a measure of inertia in the decision to

\footnotetext{
${ }^{9}$ This specification of the decision rule is often used in discrete choice models. For an application in the market for differentiated products see Anderson, de Palma, and Thisse (1992). The idea has also been applied in financial markets, by Brock and Hommes (1998) and by Lux (1998).
} 
switch to the more profitable rule ${ }^{10}$. As will be seen, this parameter is of great importance in generating bubbles.

We depart from the Brock-Hommes approach in the way we define profits. In Brock-Hommes profits are defined as the total earnings on the optimal foreign asset holdings. We define the profits as the one-period earnings of investing $\$ 1$ in the foreign asset. More formally ${ }^{11}$,

$$
\pi_{i, t}=\left[s_{t-1}\left(1+r^{*}\right)-s_{t-2}(1+r)\right] \operatorname{sgn}\left[\left(1+r^{*}\right) E_{t-2}^{i}\left(s_{t-1}\right)-(1+r) s_{t-2}\right]
$$

Thus, when agents forecasted an increase in the exchange rate and this increase is realized, their per unit profit is equal to the observed increase in the exchange rate (corrected for the interest differential). If instead the exchange rate declines, they make a per unit loss which equals this decline (because in this case they have bought foreign assets which have declined in price).

We use a concept of profits per unit invested for two reasons. First, our switching rules of equations (13) and (12) selects the fittest rules. It does not select agents. To make this clear, suppose that technical traders happen to have more wealth than fundamentalists so that their total profits exceeds the fundamentalists' profits despite the fact that the technical rule happens to be less profitable (per unit invested) than the fundamentalist rule. In this case, our switching rule will select the fundamentalists rule although the agents who use this rule make less profits (because their wealth happens to be small) than agents using chartist rules. Second, in our definition of profits agents only have to use publicly available information, i.e. the forecasting rules and the observed exchange rate changes. They don't have to know their competitor's profits.

\section{Stochastic simulation of the model}

Assuming the process of the fundamental exchange rate $s_{t}^{*}$ as exogenously given, the system of the dynamic equations (6), (7), (8), (10), (12), (13), (14), some of which are high order equations, defines a high-dimensional nonlinear discretetime model. The non-linear structure of our model does not allow for a simple analytical solution. As a result we have to use numerical simulation methods. One drawback of this approach is that we cannot easily derive general conclusions. We will compensate for this drawback in two ways: first by presenting sensitivity analyses of the numerical solutions (section 5), and second by char-

\footnotetext{
${ }^{10}$ The psychological literature reveals that there is a lot of evidence of a "status quo bias" in decision making (see Kahneman, Knetsch and Thaler(1991). This implies $\gamma<\infty$. Thus we set $0<\gamma<\infty$.

${ }^{11}$ where $\operatorname{sgn}[x]$ is defined as

$$
\operatorname{sgn}[x]=\left\{\begin{array}{cl}
1 & \text { for } x>0 \\
0 & \text { for } x=0 \\
-1 & \text { for } x<0
\end{array}\right.
$$
}

and $i=c, f$ 
acterizing the steady states and the basins of attraction within a simplified deterministic version of the model (sections 7 and 8). The simulations we perform are stochastic. Stochastic shocks occur in the model because the fundamental exchange rate is assumed to be driven by a random walk, i.e.

$$
s_{t}^{*}=s_{t-1}^{*}+\varepsilon_{t}
$$

We will assume that $\varepsilon_{t}$ is normally distributed with mean equal to 0 , and standard deviation equal to 0.1 .

We present two examples of stochastic simulations that are quite typical for the kind of dynamics predicted by our model (see figure 1). The two upper parts of figure 1 present the simulated market and fundamental exchange rates obtained in two different simulation runs, using the same parameter configurations ${ }^{12}$. The two lower parts present the corresponding shares of the chartists.

The most striking features of these simulations are the following. First, it appears that the exchange rate is very often disconnected from the fundamental exchange rate. This means that the market exchange rate follows movements that are dissociated from the fundamental rate. This is especially obvious in the first simulation run (left panels), where we find that the exchange rate is disconnected from the fundamental most of the time. In the right hand panel there are many periods of disconnection, but these are less frequent. This leads to a second feature of these exchange rate movements. There appear to be two regimes. In one regime the exchange rate follows the fundamental exchange rate quite closely. These "fundamental regimes" alternate with regimes in which the fundamental does not seem to play a role in determining the exchange rate. We will call these "non-fundamental regimes". We will also call the latter ones "bubble regimes". The nature of the latter can be seen in the lower panels of (1) Non-fundamental regimes are characterized with situations in which the chartists' weights are very close to 1 . In contrast, fundamental regimes are those during which the chartists weights are below 1 and fluctuating significantly. These two regimes appear to correspond to two types of equilibria. Thus, a fundamental regime seem to occur when the exchange rate stays within the basin of attraction of a fundamental equilibrium. In such a regime the exchange rate movements stay very close to the fundamental exchange rate. Conversely, a non-fundamental regime seems to occur when the exchange rate moves within the basins of attraction around bubble equilibria. We will analyse the nature of these two equilibria in more detail in sections 4 and 7.2 .

We also note from figure (1) that fundamental and non-fundamental regimes alternate in unpredictible ways. The left hand panels show a simulation during which bubble regimes tend to dominate, while the right hand panels show a simulation during which fundamental regimes are more frequent. The two simulations, however, were run with exactly the same parameters. The only difference is the underlying stochastics of the fundamental exchange rate. Again we will return to this feature and we will show that it has something to do

\footnotetext{
${ }^{12}$ Both the market and the fundamental exchange rates are represented in terms of deviation from the starting value $s_{0}^{*}$ of the fundamental.
} 


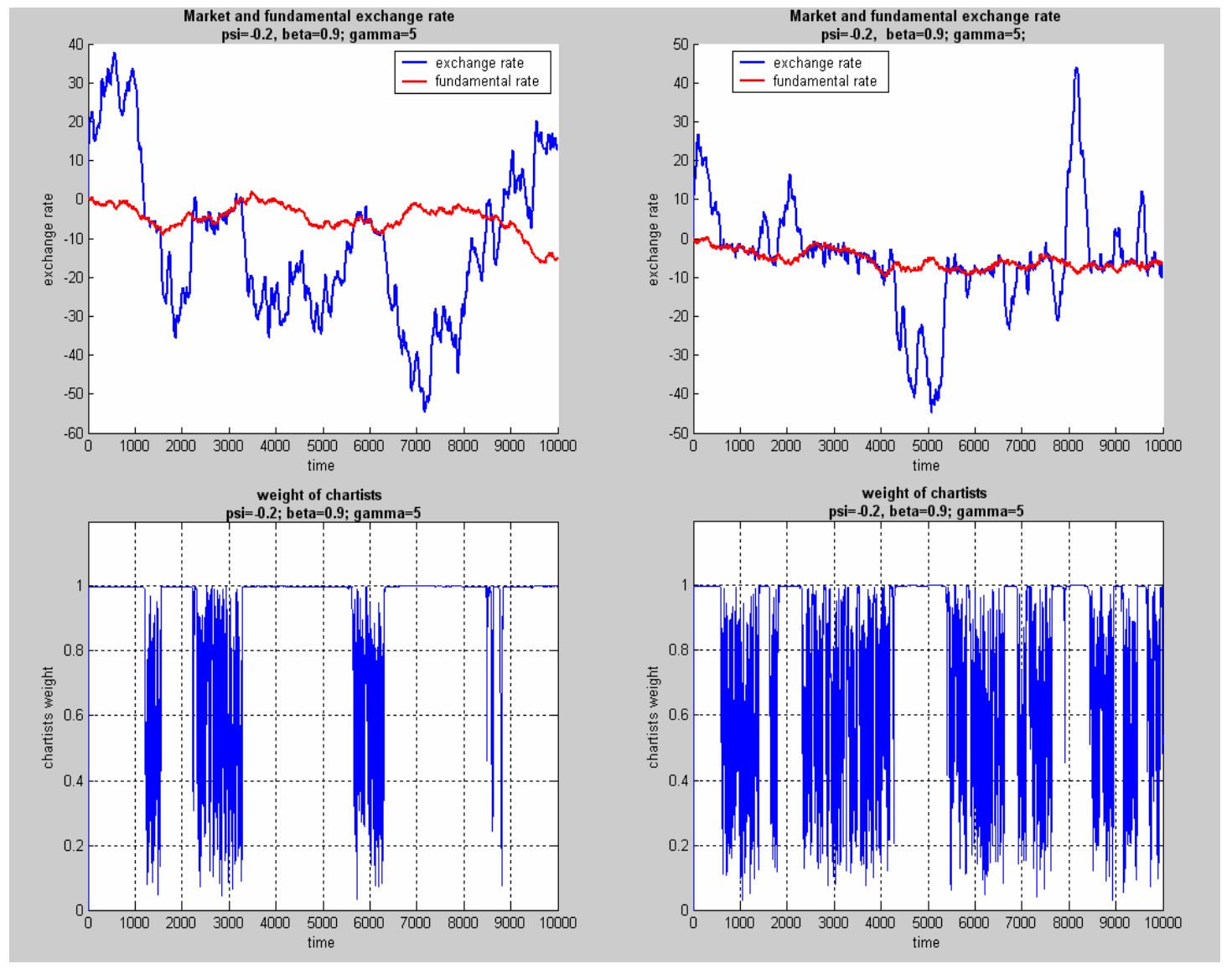

Figure 1: 
with the structure of the basins of attraction and with the discontinuities that characterize the border between fundamental and non-fundamental equilibria.

As mentioned earlier the numerical solutions are sensitive to the parameter values chosen. We illustrate this sensitivity by presenting simulations assuming different parameter values. Figure (2) shows the results of stochastic simulations of the model for different values of $\gamma$. It will be remembered that $\gamma$ measures the sensitivity of the switiching rule to risk adjusted profits. Thus when $\gamma$ is high agents react strongly to changing profitabilities of the forecasting rules they have been using. Conversely when $\gamma$ is small they do not let their forecasting rules depend much on these relative profitabilities. The results shown in figure (2) are quite remarkable. We find that when $\gamma$ is high, i.e. when agents are very sensitive to the relative profitability of the forecasting rules, the exchange rate tends to deviate strongly from the fundamental value most of the time. Thus, when $\gamma$ is high the exchange rate seems to be attracted most of the time by non-fundamental equilibria. Conversely, when agents are not very sensitive to relative profitabilities (low $\gamma$ ) the exchange rate follows the fundamental rate closely, suggesting that it is then attracted by the fundamental equilibrium most of the time.

Another important parameter in the model is the degree of risk aversion. We performed a similar sensitivity analysis and present the results in figure (3). We observe a remarkable phenomenon. When the degree of risk aversion is low the exchange rate remains very close to its fundamental value. As the degree of risk aversion $\mu$ increases the exchange rate starts to deviate increasingly from its fundamental value and the periods of disconnection tend to last longer. This suggests that when risk aversion is high the exchange rate seems to be attracted by non-fundamental equilibria. We will analyze this phenomenon in greater detail in the next sections. Here we briefly discuss the intuition behind this result. This can be explained as follows. When agents who use fundamentalist rules are very risk avert, they will not be willing to use the profit opportunities that arise during bubbles. For example when the exchange rate increases relative to its fundamental, fundamentalists expect to be able to make profits in the future from selling the overpriced foreign currency If they are very risk avert, they may not be willing to do so. As a result, there is a failure of arbitrage ${ }^{13}$. This weakens the mean reverting forces in the model.

In order to be a little more systematic about the sensitivity of the results of the model with respect to the parameters we performed the following experiment. We simulated the model for different values of the parameters $\mu$ and $\beta$. In each simulation of 10000 periods we computed the percent of the time the exchange rate deviated from the fundamental by more than 3 standard deviations of the fundamental variable during 20 consecutive periods or more. The presumption is that if the exchange rate diverges for so long and by so much it is attracted by a non-fundamental equilibrium. This conclusion may not be clear to the reader now, but it will become so when whe have analysed the deterministic

\footnotetext{
${ }^{13}$ There are other sources of failure of arbitrage that have been identified in the literature. For example, transaction costs or limits to borrowing can be reasons why arbitrage fails (see Shleifer (2000), Brunnermaier (2001)).
} 
$\gamma=5$

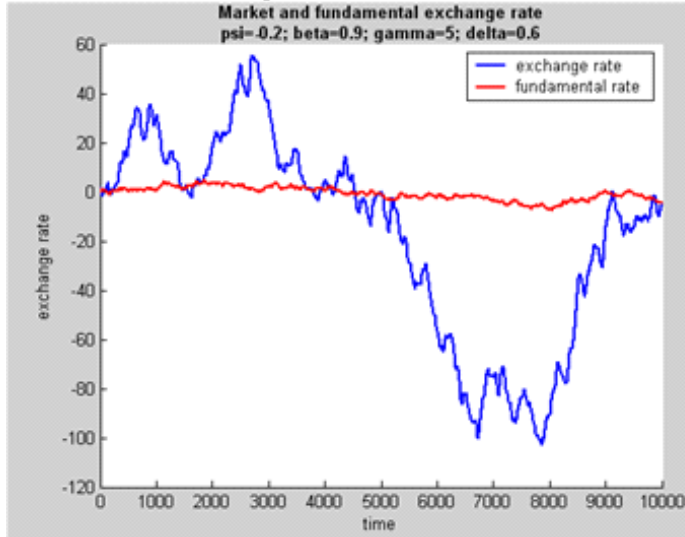

$\gamma=\mathbf{2}$

Market and fundamental exchange rate

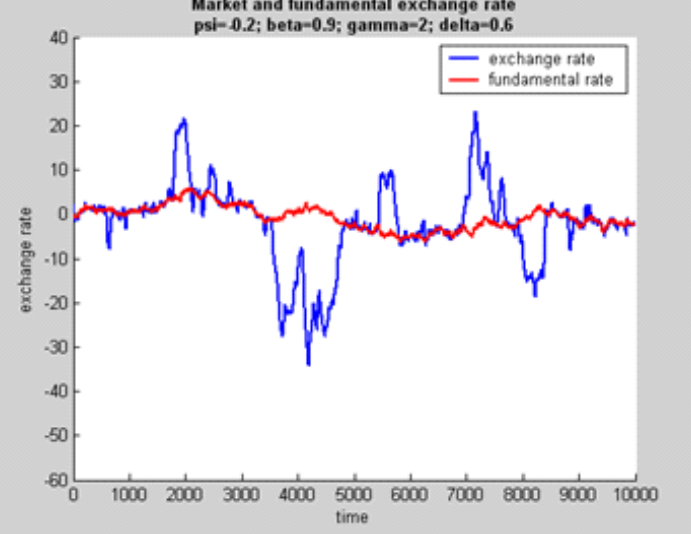

$\gamma=1$ psi- 0.2 ; beta-0.9: gal exchange rate

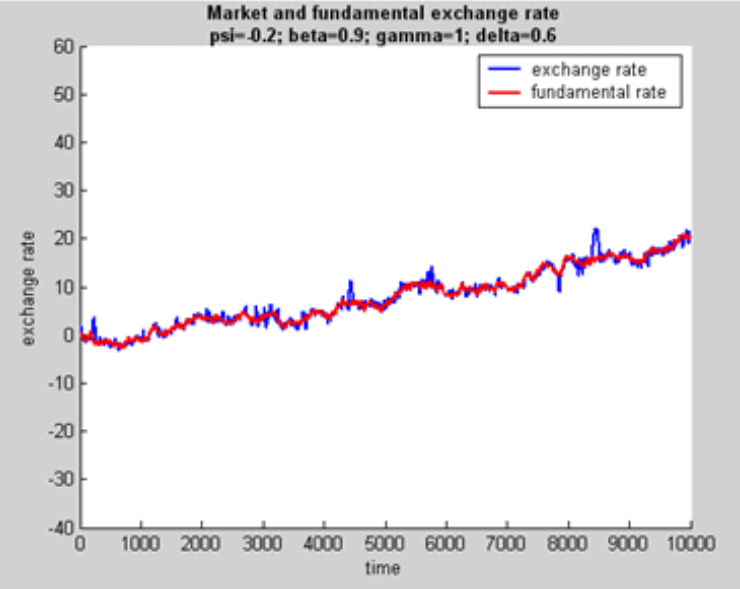

Figure 2: 
$\mu=0.1$

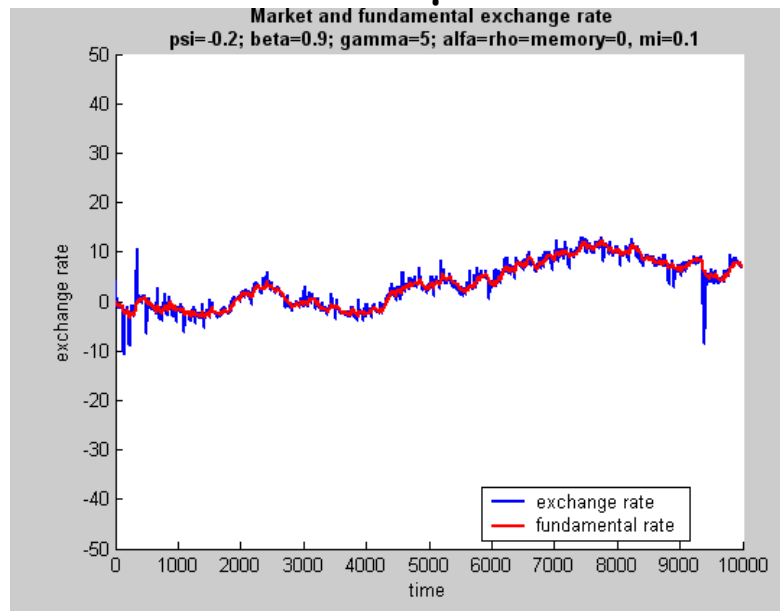

$$
\boldsymbol{\mu}=\mathbf{0 . 7 5}
$$

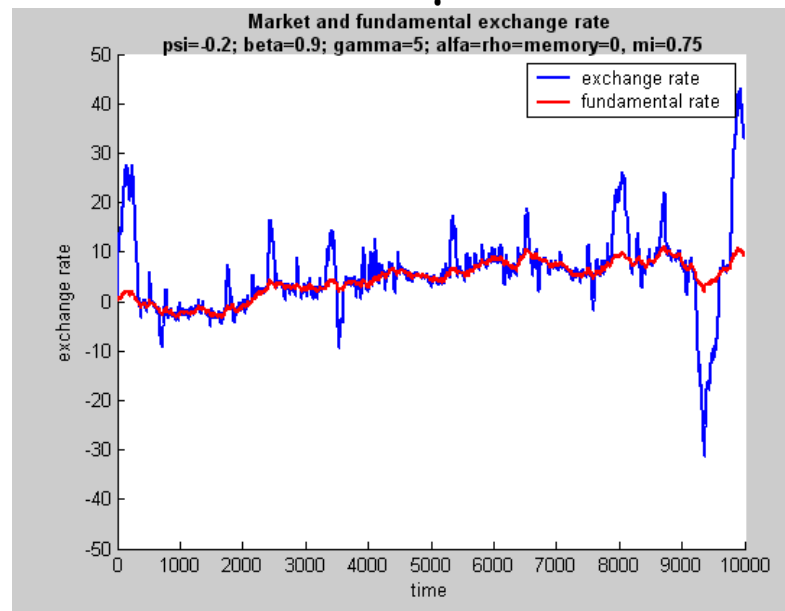

$\mu=0.5$

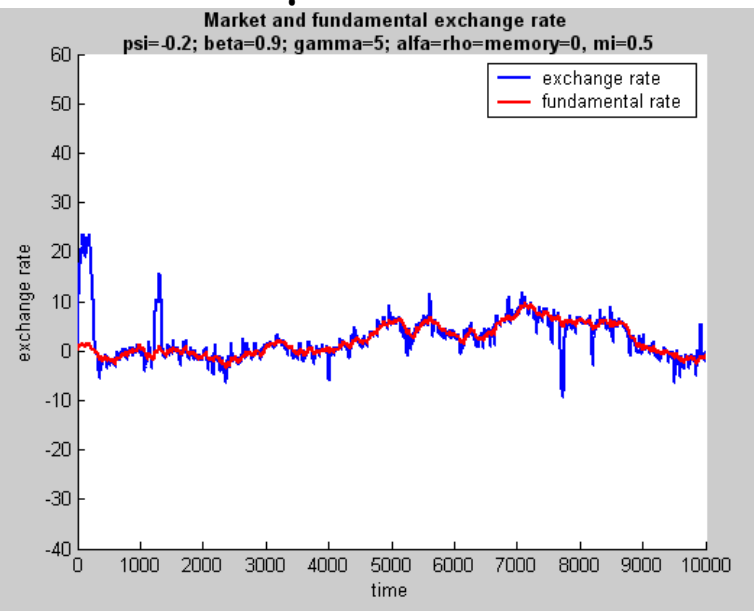

$$
\mu=1
$$

Market and fundamental exchange rate

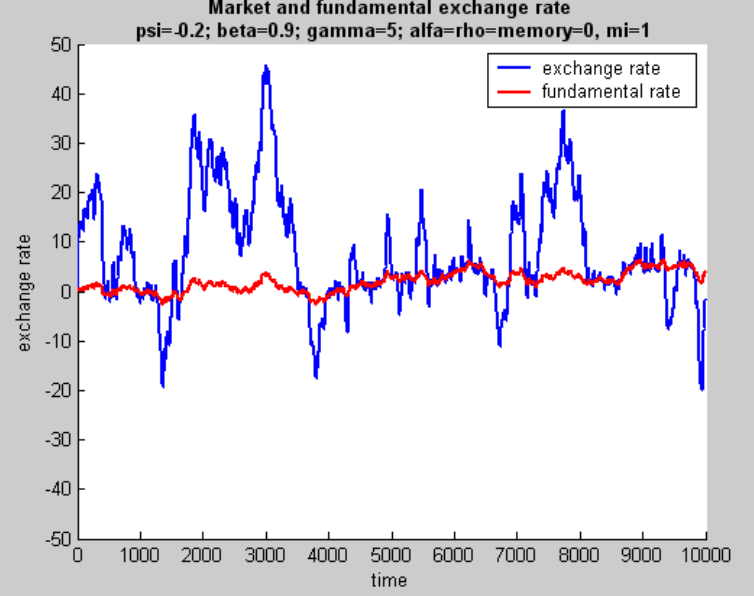

Figure 3: 
part of the model. We show the result of this exercise in the three-dimensional figure (4). On the $\mathrm{x}$ - and $\mathrm{y}$-axes we set out the parameters $\mu$ and $\beta$ respectively. On the vertical axis we show the percent of the time the exchange rate was attracted by a non-fundamental equilibrium, as defined previously. Each point corresponds to one simulation of 100000 periods for a particular combination of $\mu$ and $\beta$. We find that when $\mu$ increases the probability that the exchange rate is attracted by a non-fundamental equilibrium increases. The same conclusion holds for increases in $\beta$. The intuition of the latter result is that when chartist extrapolate past changes more, the exchange rate is likely to diverge from its fundamental for longer periods of time. We return to this point in section 8 .

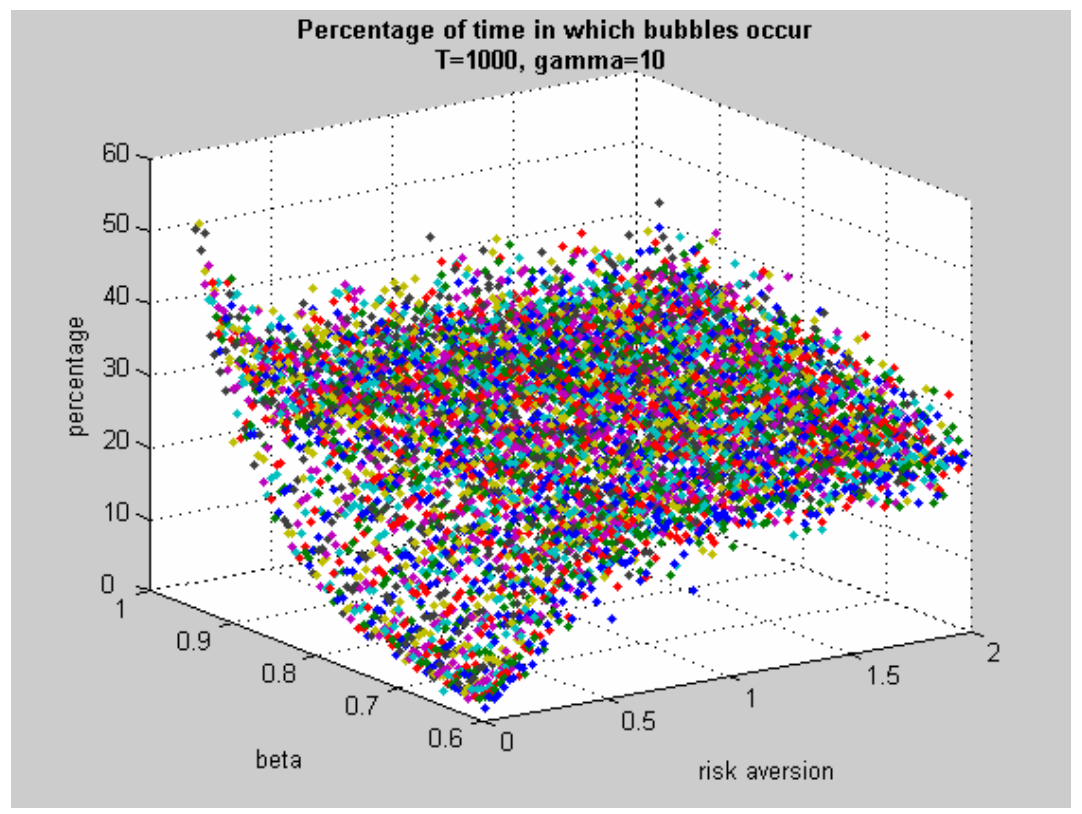

Figure 4:

\section{Numerical analysis of deterministic dynamics}

We now examine the dynamics of the deterministic part of the model, obtained by assuming a constant fundamental, which we normalize to zero ${ }^{14}$. The strong non-linearities make an analytical study of the model impossible. Therefore, we use simulation techniques which we will present in this and the following sections. We select "reasonable" values of the parameters, i.e. those that come close to empirically observed values. In appendix 2 we present a table with the

\footnotetext{
${ }^{14}$ This is equivalent to interpreting $s_{t}$ as the deviation of the market exchange rate from the constant fundamental.
} 
numerical values of the parameters of the model and the lags involved. We will analyse how sensitive the solution is to different sets of parameter values.

In figure 5 we show the long-run behavior of the exchange rate for different initial conditions. On the horizontal axis we set out the different initial conditions. These are initial shocks to the exchange rate in the period before the simulation is started ${ }^{15}$. The vertical axis shows the fixed point solutions corresponding to these different initial conditions. These were obtained from simulating the model over 10000 periods. We found that after such a long period the exchange rate had stabilized to a fixed point (a fixed attractor). We find numerically two types of fixed point solutions, that will be characterized analytically in section 7. First, for small disturbances in the initial conditions the fixed point solutions coincide with the fundamental exchange rate. As mentioned earlier, we call these solutions the fundamental equilibria. Second, for large disturbances in the initial conditions, the fixed point solutions diverge from the fundamental. These are the non-fundamental (bubble) equilibria. The larger is the initial shock (the noise) the farther the fixed points are removed from the fundamental exchange rate. The border between these two types of fixed points is characterised by discontinuities. This has the implication that in a neighbourhood of the border a small change in the initial condition (the noise) can have a large effect on the solution. We return to this issue. The different nature of these two types of fixed point attractors can also be seen from an analysis of the technical traders' weights that correspond to these different fixed point attractors. We show these technical traders' weights as a function of the initial conditions in figure 6 .

We find, first, that for small initial disturbances the technical traders' weight converges to $50 \%$ of the market. Thus when the exchange rate converges to the fundamental rate, the weight of the technical traders and the fundamentalists are equal to $50 \%$. For large initial disturbances, however, the technical traders' weight comes close 1 . Thus, when the technical traders take over most of the market, the exchange rate converges to a bubble attractor ${ }^{16}$. The meaning of a bubble attractor can now be understood better. It is an exchange rate equilibrium that is reached when the number of fundamentalists has become sufficiently small (the number of technical traders has become sufficiently large) so as to eliminate the effect of the mean reversion dynamics. It will be made clearer in section 7.2 why fundamentalists drop out of the market. Here it suffices to understand that such equilibria exist. It is important to see that these bubble attractors are fixed point solutions. Once we reach them, the exchange rate is constant. The technical traders' expectations are then model consistent, i.e. technical traders who extrapolate the past movements, forecast no change. At

\footnotetext{
${ }^{15}$ We assume five lags in our base simulation. Thus we set the exchange rates with a lag of more than one period before the start equal to the constant fundamental. This means that what we call "initial condition" in Fig. 5 is the size of one-period shocks in the exchange rate prior to the start of the simulation. All the other lagged dynamic variables are set equal to the fundamental when the simulation is started.

${ }^{16}$ In section 7 we will show that such a bubble exists when the "risk adjusted" weight of the chartists is equal to one.
} 


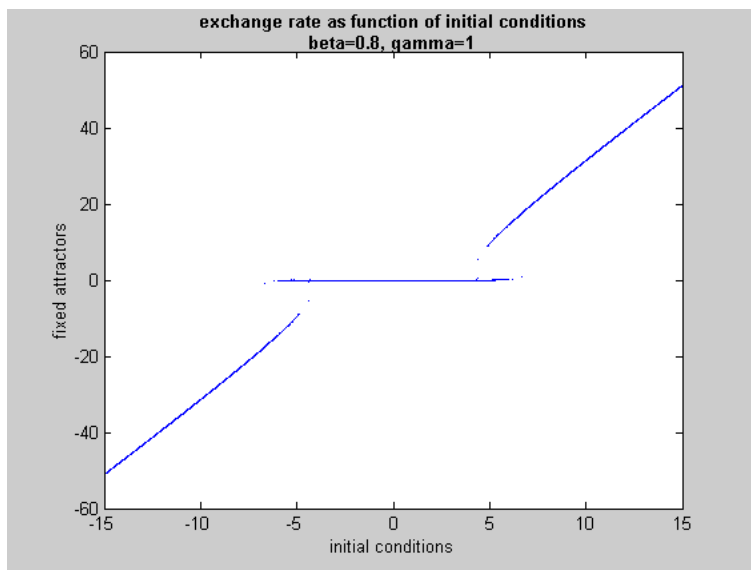

Figure 5:

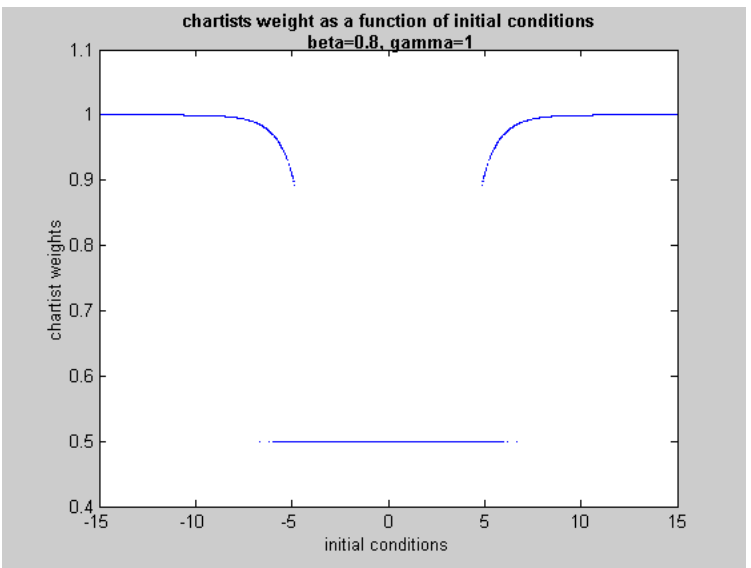

Figure 6: 
the same time, since the fundamentalists have all but left the market, there is no force acting to bring back the exchange rate to its fundamental value. Thus two types of equilibria exist: a fundamental equilibrium where technical traders and fundamentalists co-exist, and a bubble equilibrium where the technical traders have almost crowded out the fundamentalists. In both cases, the expectations of the agents in the model are consistent with the model's outcome.

\section{Sensitivity analysis}

In this section we perform a sensitivity analysis of the deterministic model. This will allow us to describe how the space of fundamental and bubble equilibria is affected by different values of the parameters of the model. In this section we concentrate on three parameters, i.e. $\mu$, (the coefficient of risk aversion), $\beta$ (the extrapolation parameter of technical traders) and $\gamma$ (the sensitivity of technical traders and fundamentalists to relative profitability).

\subsection{Sensitivity with respect to $\beta$}

We show the result of a sensitivity analysis with respect of $\beta$ in figure (7), which is a three-dimensional version of figure (5). The attractors (i.e. the fixed point solutions of the exchange rate) are shown on the vertical axis. The initial conditions are shown on the $\mathrm{x}$-axis and the different values for $\mu$ on the z-axis. Thus, the two-dimensional figure (5) is a 'slice' of figure (7) obtained for one particular value of $\beta$ (0.8 in figure (5)).

We observe that for sufficiently low values of $\beta$ we obtain only fundamental equilibria whatever the initial conditions. As $\beta$ increases the plane which represents the collection of the fundamental equilibria narrows. At the same time the space taken by the bubble equilibria increases, and these bubble equilibria tend to increasingly diverge from the fundamental equilibria. Thus as the extrapolation parameter increases, smaller and smaller shocks in the initial conditions will push the exchange rate into the space of bubble equilibria. Put differently, as $\beta$ increases, the probability of obtaining a bubble equilibrium increases.

Note also that the boundary between the fundamental and the bubble equilibria is a complex one. The boundary has a fractal dimension. We return to this issue in section 8 .

\subsection{Sensitivity with respect to $\gamma$}

The parameter $\gamma$ is equally important in determining whether fundamental or bubble equilibria will prevail. We show its importance in figure 8, which presents a similar three-dimensional figure relating the fixed attractors to both the initial conditions and the values of $\gamma$. We find that for $\gamma=0$ or close to 0 , all equilibria are fundamental ones. Thus, when agents are not sensitive to changing profitability of forecasting rules, the exchange rate will always converge to the fundamental equilibrium whatever the initial condition. As $\gamma$ increases, the 


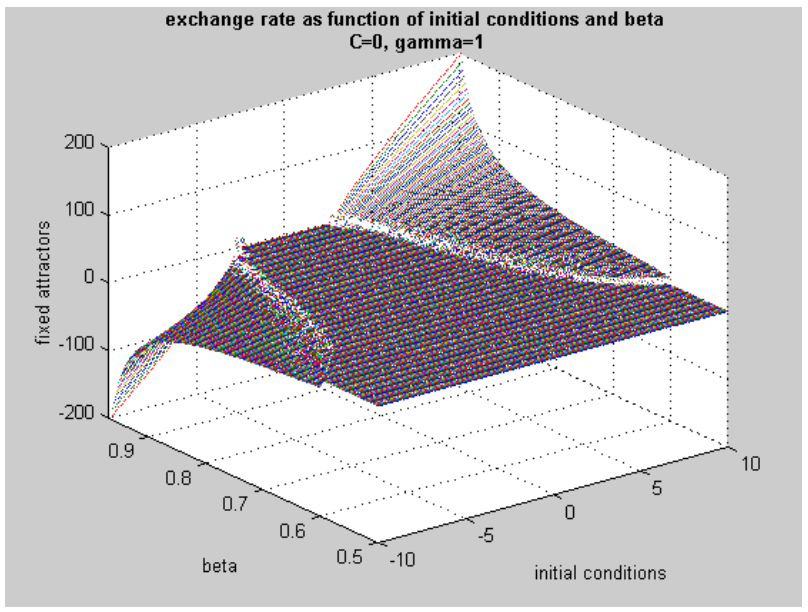

Figure 7:

space of fundamental equilibria shrinks. With sufficiently high values of $\gamma$, small initial disturbances (noise) are sufficient to push the exchange rate into a bubble equilibrium. Put differently, as $\gamma$ increases, the probability of obtaining a bubble equilibrium increases. Finally, as in the case of $\beta$, we also observe that the boundary between the bubble and fundamental equilibria is complex.

\subsection{Sensitivity with respect to $\mu$}

Finally, we study the sensitivity of the equilibria with respect to the coefficient of risk aversion, $\mu$. Figure (9) shows the results. We find that when the agents become more risk averse the space of fundamental equilibria shrinks while the space of non-fundamental equilibria becomes larger. This result forms the basis for understanding the stochastic simulations that uncovered that bubbles are larger and more likely to occur when agents are more risk averse. The intuition can now be understood better. When fundamentalists are willing to take large risks they will use the profit opportunities that arise when a bubble develops. As a result they will tend to move the exchange back towards the fundamental. This reinforces the mean reverting forces in the model thereby eliminating bubbles. Conversely, when these fundamentalists are not willing to take risks, they will not use the profit opportunities during a bubble. As a result, they will not sell when the exchange rate is overvalued (or buy when the exchange rate is undervalued), thereby eliminating the mean revering dynamics in the model. Thus in this interpretation bubble (non-fundamental) equilibria emerge because of a failure to arbitrage which itself is the result of excessive risk aversion from the part of fundamentalists.

The analysis of the basins of attraction which will be performed in section 8 will confirm the results of the above sensitivity analysis, and improve our 


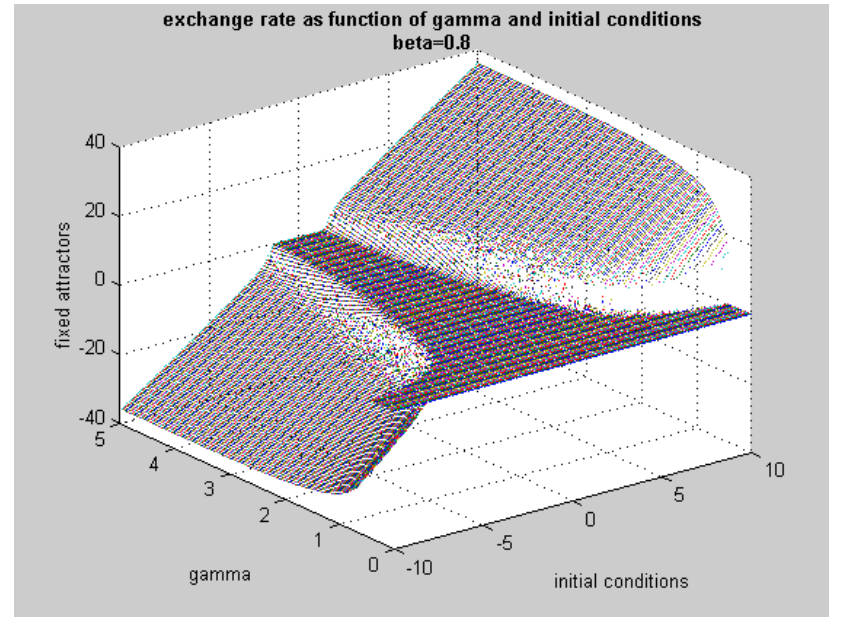

Figure 8:

understanding from a different perspective.

\section{Why crashes occur}

The model makes clear why bubbles arise in a stochastic environment. It may not be clear yet why bubbles are always followed by crashes. Here again shocks in the fundamental are of great importance. In order to analyse this issue we performed the following experiment. We fixed the initial condition at some value $(+5)$ that produces a bubble equilibrium (for a given parameter configuration). We then introduced permanent changes in the fundamental value (ranging from -10 to +10$)$ and computed the attractors for different values of $\beta$. We show the results of this exercise in figure 10. On the $\mathrm{x}$-axis we show the different fundamental values of the exchange rate, while on the $y$-axis we have the different values of $\beta$. The vertical axis shows the attractors (exchange rate solutions). The upward sloping plane is the collection of fundamental equilibria. It is upward sloping $(45 \%)$ because an increase in the fundamental rate by say 5 leads to an equilibrium exchange rate of 5 . For low values of $\beta$ we always have fundamental equilibria. This result matches the results of figure (7) where we found that for low $\beta$ 's all initial conditions lead to a fundamental equilibrium.

The major finding of figure (10) is that when permanent shocks in the fundamental are small relative to the initial (temporary) shock, $(+5)$ we obtain bubble equilibria. The corollary of this result is that when the fundamental shock is large enough relative to the noise, we obtain a fundamental equilibrium. Thus if an initial temporary shock has brought the exchange rate in a bubble equilibrium, a sufficiently large fundamental shock will lead to a crash. In a stochastic environment in which the fundamental rate is driven by a ran- 


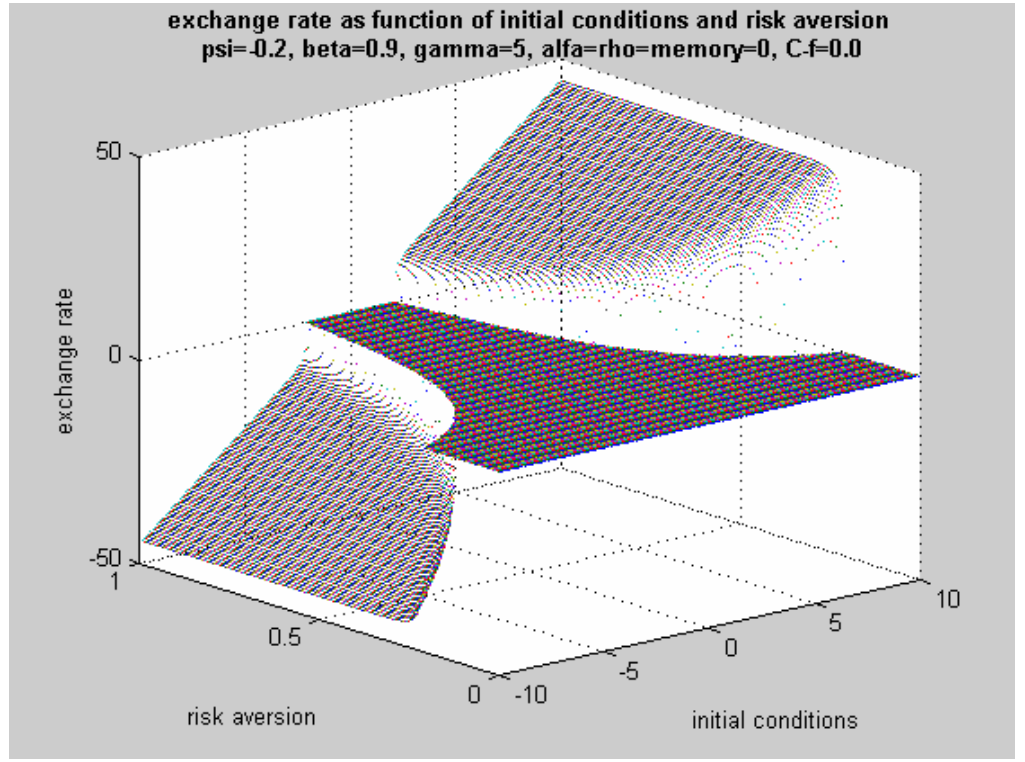

Figure 9:

dom walk (permanent shocks), any bubble must at some point crash because the attactive forces of the fundamental accumulate over time and overcome the temporary dynamics of the bubble.

The interesting aspect of this result is that the crash occurs irrespective of whether the fundamental shock is positive or negative. Since we have a positive bubble, it is easy to understand that a negative shock in the fundamental can trigger a crash. A positive shock has the same effect though. The reason is that a sufficiently large positive shock in the fundamental makes fundamentalist forecasting more profitable, thereby increasing the number of fundamentlists in the market and leading to a crash (to the new and higher fundamental rate). Put differently, while in the short run, technical traders exploit the noise to start a bubble, in the long run when the fundamental rate inexorably moves in one or the other direction, fundamentalists forecasting becomes attractive.

It is also interesting to note that as $\beta$ increases, the size of the shocks in the fundamental necessary to bring the exchange rate back to its fundamental rate increases. In a stochastic environment this means that bubbles will be stronger and longer-lasting when $\beta$ increases.

In conclusion, it is worth noting that shocks in fundamentals both act as triggers for the emergence of a bubble (see sections 4 and 5) and as triggers for its subsequent crash. The intuition can be explained as follows. When the exchange rate is in a fundamental equilibrium, an unexpected and permanent increase in the fundamental, sets in motion an upward movement of the exchange rate towards the new fundamental. This is the result of the action by 


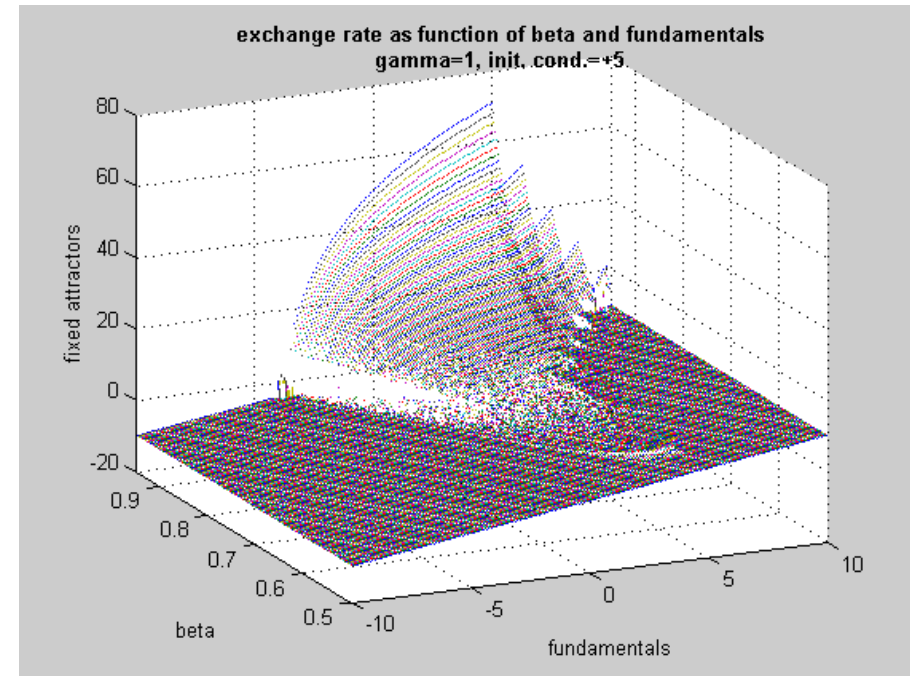

Figure 10:

fundamentalists. This upward movement, however, also makes extrapolative forecasting (technical trading) increasingly profitable and can lead to a bubble.

When the exchange rate is in a bubble equilibrium, a large enough (positive or negative) shock in the fundamental strenghtens the hand of fundamentalists' forecasting, and attracts agents towards this forecasting rule. This then leads to a crash.

As in the case of the bubble, the prediction of the timing of the crash is made difficult because of the fuzziness (complexity) of the border between bubble and fundamental equilibria (figure (10)). Thus, although crashes are inevitable, their exact timing is unknown. The remarkable aspect of this result is that it is obtained in a deterministic model.

Though the foregoing numerical study of the deterministic part of the model helps us to understand the results of the stochastic simulations, these results can be better understood by looking at the "simplified" deterministic version developed in the next section, which allows a simple analytical characterization of the steady states as well as a graphical representation of their basins of attraction.

\section{A simplified deterministic model}

In this section we investigate the analytical properties of a simplified deterministic model which is obtained by setting the stochastic error term $\varepsilon_{t}$ equal to 0 , by assuming that the variance is computed according to the adaptive equation 
$(11)^{17}$, and by assuming that technical traders only take one lag into account (i.e. we assume $\rho=0$ in eq. $(9))^{18}$. In addition, we set $r=r^{*}=0, Z=0$, and normalize the fundamental rate, $s_{t}^{*}=s^{*}=0^{19}$. In other words, we build a "minimal" deterministic dynamical system which is intended to represent the simplest form of the model, though capturing and reproducing closely the qualitative features of a class of richer and more complicated models. This will make it easier to understand the nature of the dynamics produced in the stochastic simulations.

\subsection{The dynamical system}

Equations (10), which define the variance terms can be rewritten as adaptive updating rules as follows:

$$
\begin{aligned}
\sigma_{c, t}^{2} & =(1-\theta) \sigma_{c, t-1}^{2}+\theta\left[E_{t-2}^{c}\left(s_{t-1}\right)-s_{t-1}\right]^{2} \\
\sigma_{f, t}^{2} & =(1-\theta) \sigma_{f, t-1}^{2}+\theta\left[E_{t-2}^{f}\left(s_{t-1}\right)-s_{t-1}\right]^{2}
\end{aligned}
$$

and using the definition of the forecasting rules 7 and 8 (with $\rho=0$ ), this yields

$$
\begin{gathered}
\sigma_{c, t}^{2}=(1-\theta) \sigma_{c, t-1}^{2}+\theta\left[(1+\beta) s_{t-3}-\beta s_{t-4}-s_{t-1}\right]^{2} \\
\sigma_{f, t}^{2}=(1-\theta) \sigma_{f, t-1}^{2}+\theta\left[(1-\psi) s_{t-3}-s_{t-1}\right]^{2}
\end{gathered}
$$

On the other hand, using again the forecasting rules 7 and 8 , the profits can be rewritten as follows

$$
\begin{gathered}
\pi_{f, t}=\left(s_{t-1}-s_{t-2}\right) \operatorname{sgn}\left[(1-\psi) s_{t-3}-s_{t-2}\right] \\
\pi_{c, t}=\left(s_{t-1}-s_{t-2}\right) \operatorname{sgn}\left[(1+\beta) s_{t-3}-\beta s_{t-4}-s_{t-2}\right]
\end{gathered}
$$

Now define the "risk-adjusted" weights of fundamentalists and technical traders

$$
\Theta_{f, t}=\frac{w_{f, t} / \sigma_{f, t}^{2}}{w_{f, t} / \sigma_{f, t}^{2}+w_{c, t} / \sigma_{c, t}^{2}} \quad \Theta_{c, t}=1-\Theta_{f, t}=\frac{w_{c, t} / \sigma_{c, t}^{2}}{w_{f, t} / \sigma_{f, t}^{2}+w_{c, t} / \sigma_{c, t}^{2}}
$$

where

$$
w_{f, t}=\frac{\exp \left[\gamma\left(\pi_{f, t}-\mu \sigma_{f, t}^{2}\right)\right]}{\exp \left[\gamma\left(\pi_{c, t}-\mu \sigma_{c, t}^{2}\right)\right]+\exp \left[\gamma\left(\pi_{f, t}-\mu \sigma_{f, t}^{2}\right)\right]}
$$

\footnotetext{
${ }^{17}$ This allows to reduce the number of dynamic variables. One could assume a finite number of lags, instead of the adaptive rule (11), without altering the steady state analysis.

${ }^{18}$ One can easily add additional lags without altering the steady state analysis.

${ }^{19}$ These semplification do not alter the qualitative behavior of the general model with positive interest rates, supply, and fundamental. Indeed, using simple changes of variables and interpreting $s_{t}$ as the deviation of the exchange rate from the fundamental, one could easily reduce the general model to the simplified case presented in this section.
} 
or equivalently

$$
\Theta_{f, t}=\frac{w_{f, t}\left(\sigma_{c, t}^{2} / \sigma_{f, t}^{2}\right)}{w_{f, t}\left(\sigma_{c, t}^{2} / \sigma_{f, t}^{2}\right)+\left(1-w_{f, t}\right)} \quad \Theta_{c, t}=1-\Theta_{f, t}
$$

We can then write the market clearing equation (6) as follows:

$$
\begin{aligned}
s_{t} & =s_{t-1}-\Theta_{f, t} \psi s_{t-1}+\Theta_{c, t} \beta\left(s_{t-1}-s_{t-2}\right)= \\
& =\left[1+\beta-\Theta_{f, t}(\psi+\beta)\right] s_{t-1}-\beta\left(1-\Theta_{f, t}\right) s_{t-2}
\end{aligned}
$$

With suitable changes of variables it is possible to write the dynamical system as a 6-dimensional system. Set

$$
u_{t}=s_{t-1} ; \quad y_{t}=u_{t-1}\left(=s_{t-2}\right) ; \quad z_{t}=y_{t-1}\left(=s_{t-3}\right)
$$

Then the 6 dynamic variables of the model are $\left(s_{t}, u_{t}, y_{t}, z_{t}, \sigma_{c, t}^{2}, \sigma_{f, t}^{2}\right)$. The state of the system at time $t-1$, i.e. $\left(s_{t-1}, u_{t-1}, y_{t-1}, z_{t-1}, \sigma_{c, t-1}^{2}, \sigma_{f, t-1}^{2}\right)$ determines the state of the system at time $t$, i.e. $\left(s_{t}, u_{t}, y_{t}, z_{t}, \sigma_{c, t}^{2}, \sigma_{f, t}^{2}\right)$ through the following 6-D dynamical system:

$$
\begin{gathered}
s_{t}=\left[1+\beta-\Theta_{f, t}(\psi+\beta)\right] s_{t-1}-\left(1-\Theta_{f, t}\right) \beta u_{t-1} \\
u_{t}=s_{t-1} \\
y_{t}=u_{t-1} \\
z_{t}=x_{t-1} \\
\sigma_{c, t}^{2}=(1-\theta) \sigma_{c, t-1}^{2}+\theta\left[(1+\beta) y_{t-1}-\beta z_{t-1}-s_{t-1}\right]^{2} \\
\sigma_{f, t}^{2}=(1-\theta) \sigma_{f, t-1}^{2}+\theta\left[(1-\psi) y_{t-1}-s_{t-1}\right]^{2}
\end{gathered}
$$

where

$$
\Theta_{f, t}=\frac{w_{f, t}\left(\sigma_{c, t}^{2} / \sigma_{f, t}^{2}\right)}{w_{f, t}\left(\sigma_{c, t}^{2} / \sigma_{f, t}^{2}\right)+\left(1-w_{f, t}\right)}
$$

and

$$
\begin{gathered}
w_{f, t}=\frac{\exp \left[\gamma\left(\pi_{f, t}-\mu \sigma_{f, t}^{2}\right)\right]}{\exp \left[\gamma\left(\pi_{c, t}-\mu \sigma_{c, t}^{2}\right)\right]+\exp \left[\gamma\left(\pi_{f, t}-\mu \sigma_{f, t}^{2}\right)\right]} \\
\left.\pi_{f, t}=\left(s_{t-1}-u_{t-1}\right) \operatorname{sgn}\left[(1-\psi) y_{t-1}-u_{t-1}\right)\right] \\
\pi_{c, t}=\left(s_{t-1}-u_{t-1}\right) \operatorname{sgn}\left[y_{t-1}+\beta\left(y_{t-1}-z_{t-1}\right)-u_{t-1}\right]
\end{gathered}
$$

We are now able to derive analytically the steady states of the simplified model. 


\subsection{Analytical characterization of the steady states}

The steady states are obtained by setting

$\left(s_{t-1}, u_{t-1}, y_{t-1}, z_{t-1}, \sigma_{f, t-1}^{2}, \sigma_{c, t-1}^{2}\right)=\left(s_{t}, u_{t}, y_{t}, z_{t}, \sigma_{f, t}^{2}, \sigma_{c, t}^{2}\right)=\left(\bar{s}, \bar{u}, \bar{y}, \bar{z}, \bar{\sigma}_{f}^{2}, \bar{\sigma}_{c}^{2}\right)$

in the dynamical system (24)-(29). Notice however that this implies, first of all, $\bar{\sigma}_{c}^{2}=0$ at a steady state. Note also that the points for which $\sigma_{c}^{2}=\sigma_{f}^{2}=0$ (denote by $\Omega$ the set of such points) do not belong to the state space of the system, because in this case the ratio $\sigma_{c, t}^{2} / \sigma_{f, t}^{2}$ is not defined. This fact does not exclude that, for a given set of initial conditions, trajectories converge to some point in the set $\Omega$, provided that the ratio $p_{t} \equiv \sigma_{c, t}^{2} / \sigma_{f, t}^{2}$ admits a limit ${ }^{20}$. Indeed for a wide set of initial conditions, as our numerical simulations reveal, trajectories do converge to such a point, while the ratio between variances converges to a positive value (to 1 in our simulations ${ }^{21}$ ). This allows the algebraic manipulation of this "boundary solution" as a "steady state" where $\bar{\sigma}_{f}^{2}=\bar{\sigma}_{c}^{2}=0$, but $\bar{p} \equiv \bar{\sigma}_{c}^{2} / \bar{\sigma}_{f}^{2}>0$. Such an heuristic will be useful in order to characterize the "steady states" of the underlying deterministic model, though the deterministic model can only be interpreted as an unrealistic limiting case of the stochastic model ${ }^{22}$. With this preliminary remark, using (34), we can write a set of conditions that a steady state must satisfy

$$
\begin{gathered}
\bar{s}=\bar{u}=\bar{y}=\bar{z} \\
\bar{\pi}_{f}=\bar{\pi}_{c}=0 \\
\bar{\sigma}_{c}^{2}=0 \quad \bar{\sigma}_{f}^{2}=\psi^{2} \bar{s}^{2} \\
\bar{w}_{f}=\frac{\exp \left[-\gamma \mu \bar{\sigma}_{f}^{2}\right]}{1+\exp \left[-\gamma \mu \bar{\sigma}_{f}^{2}\right]} \quad \bar{\Theta}_{f}=\frac{\bar{w}_{f} \bar{p}}{\bar{w}_{f} \bar{p}+\left(1-\bar{w}_{f}\right)} \\
\bar{\Theta}_{f} \psi \bar{s}=0
\end{gathered}
$$

In particular eq. (39) is obtained from (24). It can now be shown that the model produces two types of "steady state" solutions. We analyse these consecutively.

\subsubsection{Fundamental steady state}

First of all, the model allows for a steady state where the exchange rate is equal to the fundamental (which is normalised to 0 ). In order to see this, note that when $\bar{s}=0$, condition (39) is fulfilled with any (non negative) $\bar{\Theta}_{f}$. In particular, we look for steady states characterized by $\bar{\Theta}_{f}>0$. From (38) this implies $\bar{p} \equiv \bar{\sigma}_{c}^{2} / \bar{\sigma}_{f}^{2}>0$ at the "steady state". Given that $\bar{\sigma}_{c}^{2}=0$, condition

\footnotetext{
${ }^{20}$ For a deep analytical and numerical investigation of the behavior of dynamical systems where at least one equation has a component which takes the form $0 / 0$ in some points, see Bischi et al. (1999).

${ }^{21}$ We show this in appendix 1 where we plot the ratio as a function of time

${ }^{2}$ Note, for instance, that the agents' demand (3) is defined only when the variance term is strictly positive.
} 
$\bar{p}>0$ can only occur when also $\bar{\sigma}_{f}^{2}=0$. Therefore, from (38) we get $\bar{w}_{f}=1 / 2$ and $\bar{\Theta}_{f}=\bar{p} /(\bar{p}+1)$ (in particular $\bar{\Theta}_{f}=1 / 2$ if $\bar{p}=1$, as is the case of our numerical experiments).

The "fundamental" steady state is characterized by the exchange rate being at its fundamental level, by zero profits and zero risk, and by fundamentalist and technical trader fractions equal to $1 / 2^{23}$.

\subsubsection{Non-fundamental steady states}

The model allows for a second type of steady state solution. This is a solution in which the exchange rate is constant and permanently different from its (constant) fundamental value. In other words the simplified deterministic model ${ }^{24}$ allows for constant non-zero exchange rates in the steady state. The existence of such equilibria can be shown as follows. From condition (39) it can easily be seen that if $\bar{\Theta}_{f}=0$ any constant exchange rate $\bar{s}$ will satisfy this equation, i.e. the exchange rate is not required to be at the fundamental. From (38) we find that a necessary and sufficient condition for $\bar{\Theta}_{f}$ to be zero is that $\bar{\sigma}_{c}^{2}=0$ and $\bar{\sigma}_{f}^{2}>0$ (i.e. $\left.\bar{p}=0\right)$. Note that in this case $\bar{\Theta}_{c} \equiv 1-\bar{\Theta}_{f}=1$, and $\bar{\sigma}_{f}^{2}=\psi^{2} \bar{s}^{2}$. Put differently, there exist steady state solutions with the following characteristics: the exchange rate deviates from the fundamental by a constant amount; thus, fundamentalist forecasting rules lead to a constant error and therefore the risk adjusted share of fundamentalist rules is zero ${ }^{25}$. The latter is necessary, otherwise agents would still be using the rule so that their forecast of a reversion to the fundamental would move the exchange rate.

As mentioned earlier, we call a non-fundamental equilibrium a "bubble equilibrium". We call it a bubble equilibrium because it is an equilibrium in which fundamentalists exert no influence on the exchange rate. It should be stressed that this definition of a bubble is very different from the "rational bubble" which is defined as an unstable path of the exchange rate. It comes closer to the notion of "sunspots" which is also an equilibrium concept in rational expectations models (see Blanchard and Fischer(1989), p255). We will come back to this in section 9 where we will contrast our bubble equilibria with sunspot equilibria.

With this dynamical system it is not possible to perform the local stability analysis of the steady state with the usual techniques, based upon the analysis

\footnotetext{
${ }^{23}$ As an alternative, we could characterize a fundamental steady state as one where the ratio between variances is positive. This allows to derive it in an alternative way. Assume that $\bar{p} \equiv \bar{\sigma}_{c}^{2} / \bar{\sigma}_{f}^{2}>0$. Given that $\bar{\sigma}_{c}^{2}=0$, this can only occur provided that $\bar{\sigma}_{f}^{2}=0$, which in turn implies $\bar{s}=0$ from (37). Furthermore from (38) we get $\bar{w}_{f}=1 / 2$, and therefore $\bar{\Theta}_{f}=\bar{p} /(\bar{p}+1)>0$. Again, this necessarily implies $\bar{s}=0$ in order condition (39) be satisfied.

${ }^{24}$ Where the fundamental value is normalized to zero

${ }^{25}$ Note that this does not imply that the share of the fundamentalists $\bar{w}_{f}$ is zero, as can be seen from the first equation in (38), which becomes

$$
\bar{w}_{f}=\frac{\exp \left[-\gamma \mu \psi^{2} \bar{s}^{2}\right]}{1+\exp \left[-\gamma \mu \psi^{2} \bar{s}^{2}\right]}
$$

However, the more the exchange rate deviates from the fundamental at the steady state, the closer to zero is the share of the fundamentalists.
} 
of the eigenvalues of the Jacobian matrix evaluated at the steady state. Apart from the high dimension of the dynamical system, a first problem arises from the fact that what we call "fundamental steady state" is a point which does not belong to the state space of the deterministic system, though it attracts the trajectories of the system. Furthermore, in general the "map" whose iteration generates the dynamics is not differentiable in the points which belong to the locus $s=u=y=z$ (see the equations of the profits (32) and (33)), which includes the set of the steady states of the model.

\section{A graphical inspection of the basins of attrac- tion}

In this section we return to the results of the numerical experiments performed in the previous sections, and interpret them from a different point of view, namely the perspective of the deterministic structure of the basins of attraction ${ }^{26}$. In particular, this approach provides a better understanding of the bubbles and crashes of the stochastic model (sections 3 and 6 ), and of the sensitivity with respect to the key parameters $\beta, \gamma$, and $\mu$ (section 5 ).

As remarked in section 7 , the analytical derivation of the steady states demonstrates that a fundamental equilibrium coexists in the phase-space of the deterministic model with bubble equilibria. Given that in our numerical study of the deterministic part (sections 4 and 5) the exchange rate is attracted towards the fundamental or towards a bubble depending on the initial condition, we can conclude that these co-existing equilibria are both locally stable, at least for wide ranges of the key parameters, though the non-differentiability of the dynamical system prevents analytical results about the local asymptotic stability properties of the steady states. Although changes of the parameters do not affect the local stability properties of the equilibria, they do modify the "size" of the basins of attraction and the structure of the basin boundary between the two kinds of equilibria. An analysis of the parameter dependence of the basins in a high-dimensional nonlinear system like the present one can only be performed via numerical simulation and graphical inspection. In a two-dimensional system with coexisting steady states (or other attractors), a graphical visualization of the basins of attraction can be easily obtained by letting the initial condition $\left(X_{0}, Y_{0}\right)$ vary in the phase-plane, and marking the point $\left(X_{0}, Y_{0}\right)$ with different colors according to the asymptotic behavior of the trajectory generated by the initial condition (i.e. according to which steady state attracts that initial condition).

In the case of a $n$-dimensional dynamical system, both the phase-space and the basins of attraction are $n$-dimensional. In order to get a two-dimensional representation of the basins in this case, one needs to fix the initial values of $(n-2)$ state variables and vary the initial values of the remaining two variables.

\footnotetext{
${ }^{26}$ The basin of attraction of an attractor $\mathcal{A}$ is the subset of the phase space whose points generate trajectories converging to $\mathcal{A}$.
} 
In our model, though the phase-space is 6-dimensional, we represent the basins in the two-dimensional $(u, s)$ plane $^{27}$, by arbitrarily fixing the initial values $y_{0}$, $z_{0}, \sigma_{f, 0}^{2}, \sigma_{c, 0}^{2}$ of the state variables $y, z, \sigma_{f}^{2}, \sigma_{c}^{2}$, while the initial values of $u$ and $s\left(u_{0}\right.$ and $\left.s_{0}\right)$ are let to vary in the $(u, s)$ plane, with $u_{0}$ on the horizontal axis and $s_{0}$ on the vertical axis. Given the initial condition $\left(u_{0}, s_{0}, y_{0}, z_{0}, \sigma_{f, 0}^{2}, \sigma_{c, 0}^{2}\right)$, we run a sufficiently high number of iterations. If the state vector converges to (i.e. arrives sufficiently close to) the fundamental steady state, the initial point $\left(u_{0}, s_{0}\right)$ is marked with light grey; while if the state vector converges to a non fundamental steady state, then we mark the initial point $\left(u_{0}, s_{0}\right)$ with dark grey. Of course the representation that we obtain also depends on the fixed initial values of $y, z, \sigma_{f}^{2}, \sigma_{c}^{2}$ : under a different choice of $y_{0}, z_{0}, \sigma_{f, 0}^{2}, \sigma_{c, 0}^{2}$, we would get different pictures, because in this case we would represent the basins taking the initial condition along a different slice or section of the high-dimensional phasespace. Note that in general changes of the parameters can affect the structure of the basins. For computational reasons, the following analysis of the basins of attraction is performed on the dynamics of the simplified model (24)-(29). The parameters $\psi$ and $\theta$ are set to the values $\psi=0.2$ and $\theta=0.6$, respectively, while the parameters $\beta, \gamma$ and $\mu$ are allowed to vary. Though we are going to present only a few meaningful examples, similar qualitative results can be easily found by choosing different ranges of the parameters.

\subsection{Basins of attraction around the fundamental steady state: the frequency of bubbles}

We start with the basins of attraction around the fundamental steady state. The basins of attraction represented in Figs. 11, 12, 13 provide an intuitive explanation of the sensitivity of the long-run behavior of the exchange rate with respect to $\beta, \gamma, \mu$, respectively. In Fig. 11 the basins of the fundamental and bubble equilibria are represented under increasing values of $\beta$. What emerges is that the both the size of the basins and the shape of the basin boundary are greatly affected by the change of the parameter. Similar changes are observed under increasing values of $\gamma$ and $\mu$ (Figs. 12,13). We now describe these changes and discuss the effect on the dynamics of the stochastic model. The effect is twofold. On one hand the size of the basin of the bubble equilibria increases, and the basin boundary comes closer and closer to the fundamental equilibrium. In the stochastic model, this increases the probability that a bubble starts: indeed, the noise in the underlying fundamental has the effect of displacing (in the phasespace) the point which represents the state of the system ${ }^{28}$. If the state of the

\footnotetext{
${ }^{27}$ I.e. the plane $\left(s_{t-2}, s_{t-1}\right)$.

${ }^{28}$ Consider the system at time $t$. For fixed values of $s_{t-2}, s_{t-3}, \sigma_{f, t}^{2}, \sigma_{c, t}^{2}$, a particular state $\left(s_{t}, s_{t-1}, s_{t-2}, s_{t-3}, \sigma_{f, t}^{2}, \sigma_{c, t}^{2}\right)$ of the system at time $t$ can be represented by a point in the two-dimensional $(u, s)$-plane. Since the fundamental is set equal to zero in the deterministic model (which is equivalent to interpreting $s_{t}$ as the deviation of the exchange rate from the fundamental $s_{t}^{*}$ ) an exogenous upward (downward) shock in the fundamental $s_{t-1}^{*}$ is equivalent to a shift to the left (right) of the point in the $(u, s)$-plane, while an upward (downward) shock in $s_{t}^{*}$ is equivalent to a downward (upward) shift of the same point. As a consequence of these
} 
system at time $t$ is in the basin of attraction of the fundamental and even close to the fundamental itself, a fundamental shock may push the phase point beyond the basin boundary, in the basin of the bubble equilibrium: a quick look at the basin representation suggests that the probability of crossing the boundary and starting the bubble (for equal size of the shock) is higher for higher values of $\beta, \gamma$, or $\mu$. On the other hand, the boundary between the basins becomes more and more complex, and takes a fractal structure. This makes more and more difficult to predict the final outcome determined by a given initial condition, even in the deterministic model where the noise term is set equal to zero (as already shown in section 4). Examples of the fractal structure of the boundary, which emerges for sufficiently high values of $\beta$ and $\gamma$, are in Figs. 11c,d, 12c,d.

\subsection{Basins of attraction around bubble equilibria: why crashes occur}

Let us now consider the structure of the basins of attraction around "bubble" equilibria. Figs. 14 and 15 provide a graphical explanation of why a crash occurs: the reason of crash is related to the structure of the basins of attraction around a bubble equilibrium. In order to see this, in Figs. 14 and 15 we select a particular bubble equilibrium with $\bar{s}(=\bar{u}=\bar{y}=\bar{z})=10, \bar{\sigma}_{c}^{2}=0, \bar{\sigma}_{f}^{2}=\psi^{2} \bar{s}^{2}=4$, and we represent the basins of attraction by varying the initial condition in a neighborhood of this particular bubble equilibrium. In order to get a twodimensional representation we let $u_{0}$ and $s_{0}$ vary in the $(u, s)$-plane and fix the initial values of the other variables to their (bubble) equilibrium levels. Starting from a given parameter configuration, we obtain the representation of the basins under increasing values of $\beta$ (Fig. 14) and $\gamma$ (Fig. 15). For sufficiently low values of $\beta$ and $\gamma$, we get that the bubble equilibrium lies very close to the boundary of its basin of attraction (see Figs. 14a,b, Figs. 15a,b), which means that once the system is close to a bubble equilibrium a small fundamental shock may push the system again in the basin of attraction of the fundamental equilibrium, thus causing a crash. Also, it is clear from the same pictures that the crossing of the boundary may be caused both by a negative fundamental shock and by a positive one. Moreover, similar to the basin structure in a neighborhood of a fundamental steady state, also around bubble equilibria the boundary of the basins may have a complex structure.

However, the structure of the basins is highly affected by the parameters $\beta$ and $\gamma$. Precisely, as shown in Figs. 14c,d, Fig. 15c,d, higher values of $\beta$ and $\gamma$ determine an enlargement of the basin around the bubble ${ }^{29}$, so that the distance between the steady state and the basin boundary is greater. In a stochastic environment this will determine stronger and longer-lasting bubbles for higher $\beta$ and $\gamma$.

We have obtained graphical representations of the basins around bubble equilibria characterized by different stationary exchange rates, with very similar

shocks, the exchange rate at time $t$ may be moved into a different basin of attraction, so that the trajectory starts to move towards a different kind of attractor.

${ }^{29}$ Through a kind of "connection" with other portions of the basin. 
Basins of attraction around the fundamental steady state:

Basins of attraction sensitivity with respect to $\beta$

$\square$ fundamental
$\square$ bubble

initial condition

$\mathrm{y}_{0}=\mathrm{z}_{0}=0 \quad \sigma_{\mathrm{f}, 0}^{2}=\sigma_{\mathrm{c}, 0}^{2}=0.05 \quad \mathrm{u}_{0}$ and $\mathrm{s}_{0}$ varying

parameters

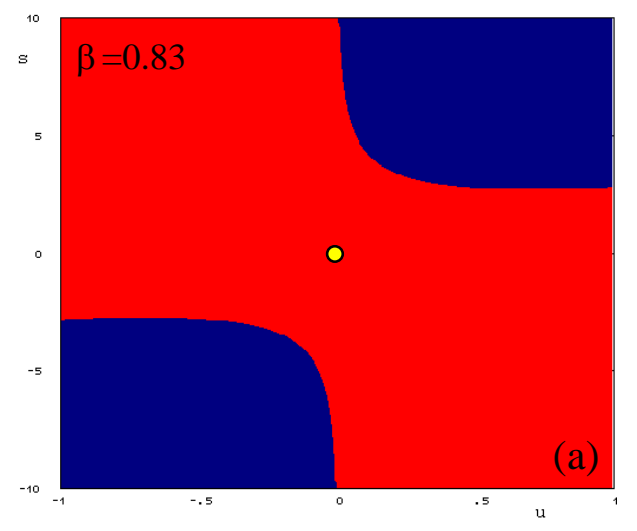

$\psi=0.2 \quad \mu=1 \quad \gamma=1 \quad \theta=0.6$
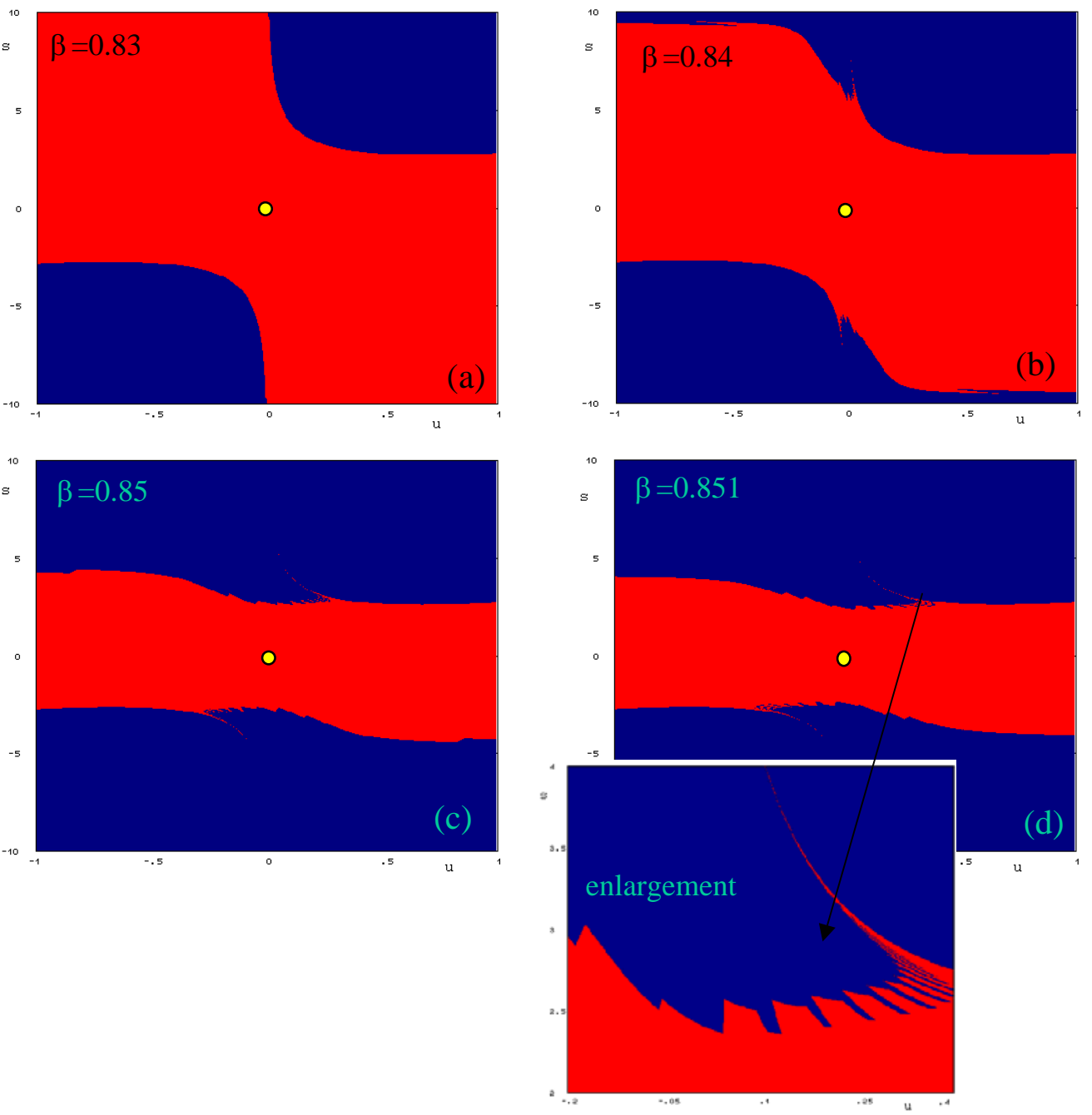

Figure 11: 
Basins of attraction around the fundamental steady state: sensitivity with respect to $\gamma$

initial condition

$\mathrm{y}_{0}=\mathrm{z}_{0}=0 \quad \sigma_{\mathrm{f}, 0}^{2}=\sigma_{c, 0}^{2}=0.05 \quad \mathrm{u}_{0}$ and $\mathrm{s}_{0}$ varying
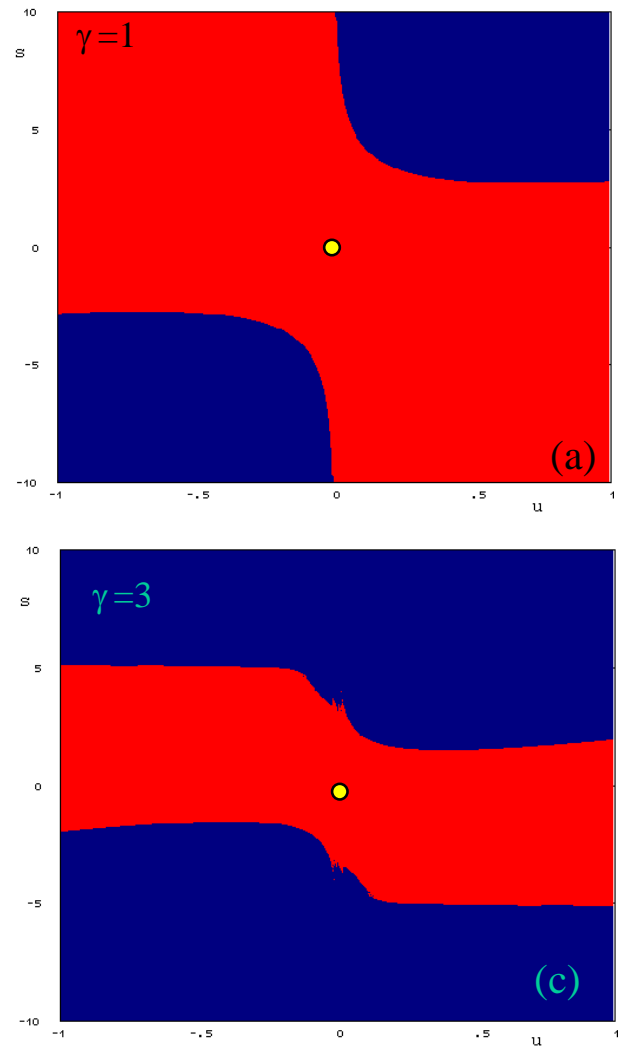

\section{parameters}

$\psi=0.2 \quad \mu=1 \quad \beta=0.83 \quad \theta=0.6$

Figure 12: 
Basins of attraction around the fundamental steady state sensitivity with respect to $\mu$

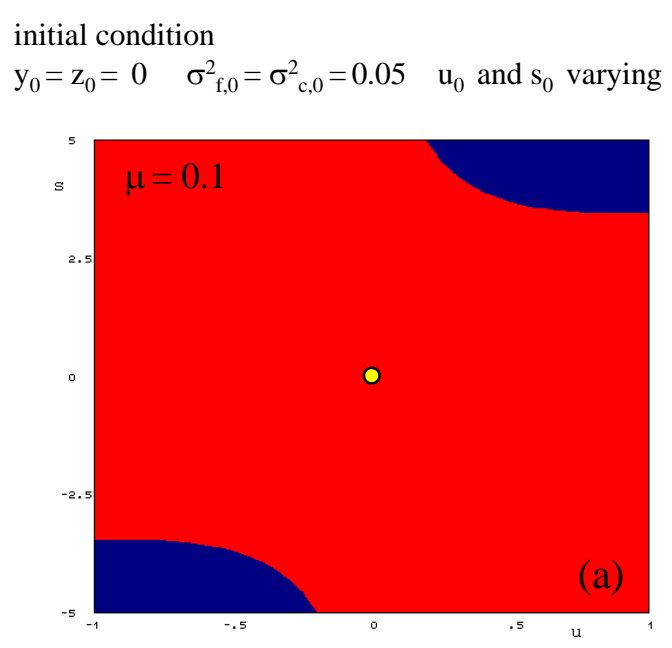

parameters

$\psi=0.2 \quad \beta=0.8 \quad \gamma=5 \quad \theta=0.6$

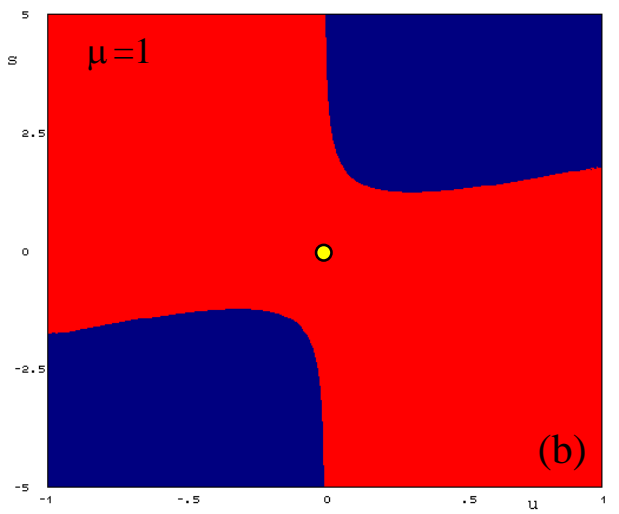

Figure 13:

results, i.e. with a basin boundary which is quite close to the bubble equilibrium, at least for sufficiently low values of $\beta$ and $\gamma^{30}$. We could say that a "fully developed" bubble represents a kind of locally stable state, but "practically" unstable once exogenous noise is added to the deterministic dynamical system.

\section{Rational versus "behavioural" bubbles}

We can now contrast the difference between "rational bubbles" and the bubbles obtained in our model, which we will label "behavioural" bubbles. A "rational bubble" is obtained in a model in which agents use all available information including the underlying structure of the model and in which they know the distribution of the underlying stochastic variables. In such a model bubbles are movements of the exchange rate (asset price) along an explosive path. The latter is one of the infinitely many unstable solutions obtained in a rational expectations model where agents are fully and perfectly informed.

In models with perfectly and fully informed agents modeling a crash is a challenging task. In a perfect foresight model a bubble with a crash cannot exist because when the timing of the crash is known (and by definition this is known in a perfect foresight model) agents will anticipate this and by backward induction

\footnotetext{
${ }^{30}$ For instance, qualitatively similar pictures can be obtained by representing the basins of attraction around the bubble equilibrium with stationary levels $\bar{s}(=\bar{u}=\bar{y}=\bar{z})=5, \bar{\sigma}_{c}^{2}=0$, $\bar{\sigma}_{f}^{2}=\psi^{2} \bar{s}^{2}=1$, under the following parameter configuration: $\beta=0.85, \gamma$ increasing from 0.25 to 2 .
} 
Basins of attraction around a "bubble equilibrium": sensitivity with respect to $\beta$

\section{parameters}

$\psi=0.2 \quad \gamma=1 \quad \mu=1 \quad \theta=0.6$

initial condition

$\mathrm{y}_{0}=\mathrm{z}_{0}=10 \quad \sigma_{\mathrm{f}, 0}^{2}=4 \quad \sigma_{\mathrm{c}, 0}^{2}=0 \quad \mathrm{u}_{0}$ and $\mathrm{s}_{0}$ varying
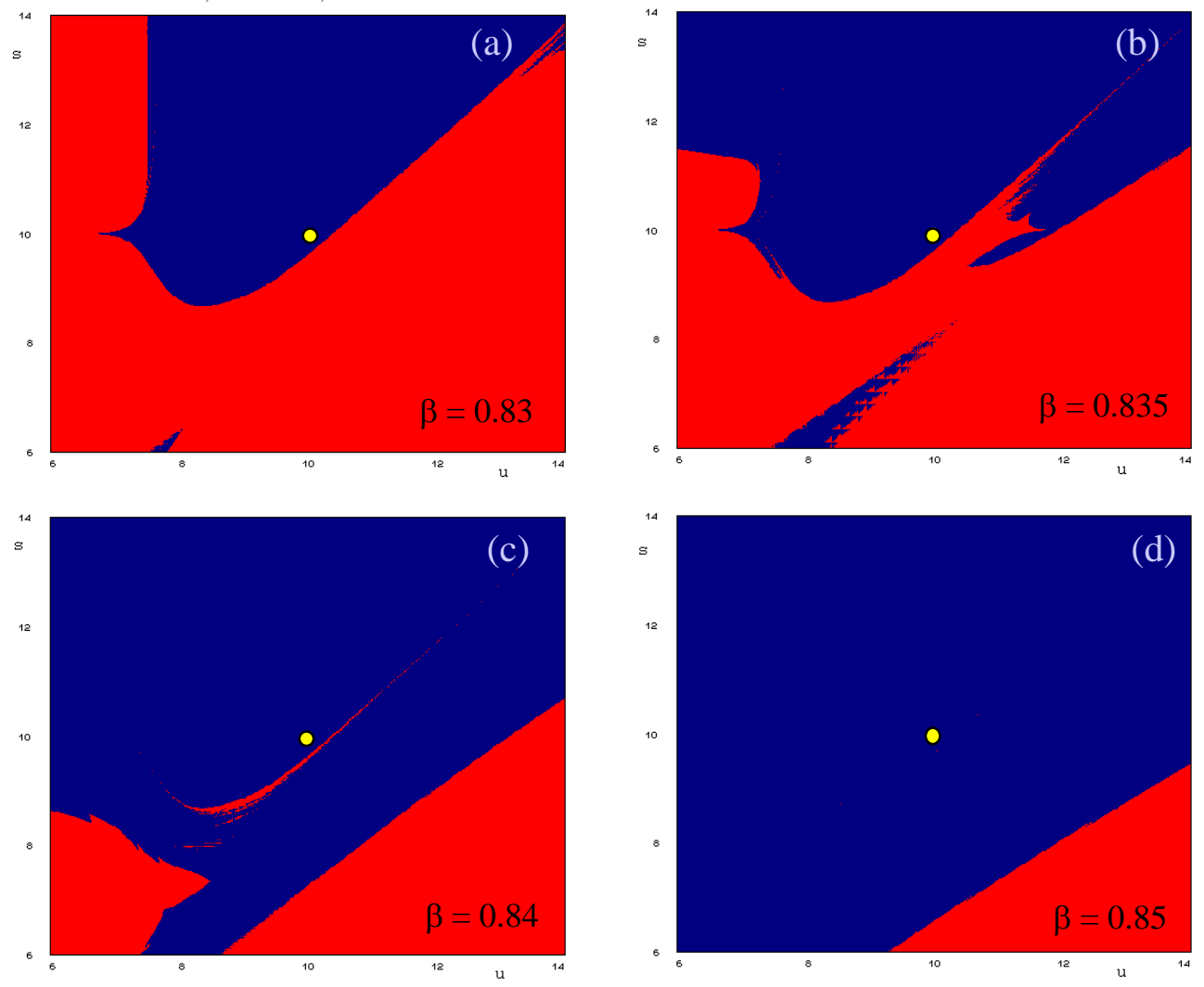

Figure 14: 
Basins of attraction around a "bubble equilibrium": sensitivity with respect to $\gamma$

initial condition

parameters

$\psi=0.2 \quad \beta=0.83 \mu=1 \quad \theta=0.6$
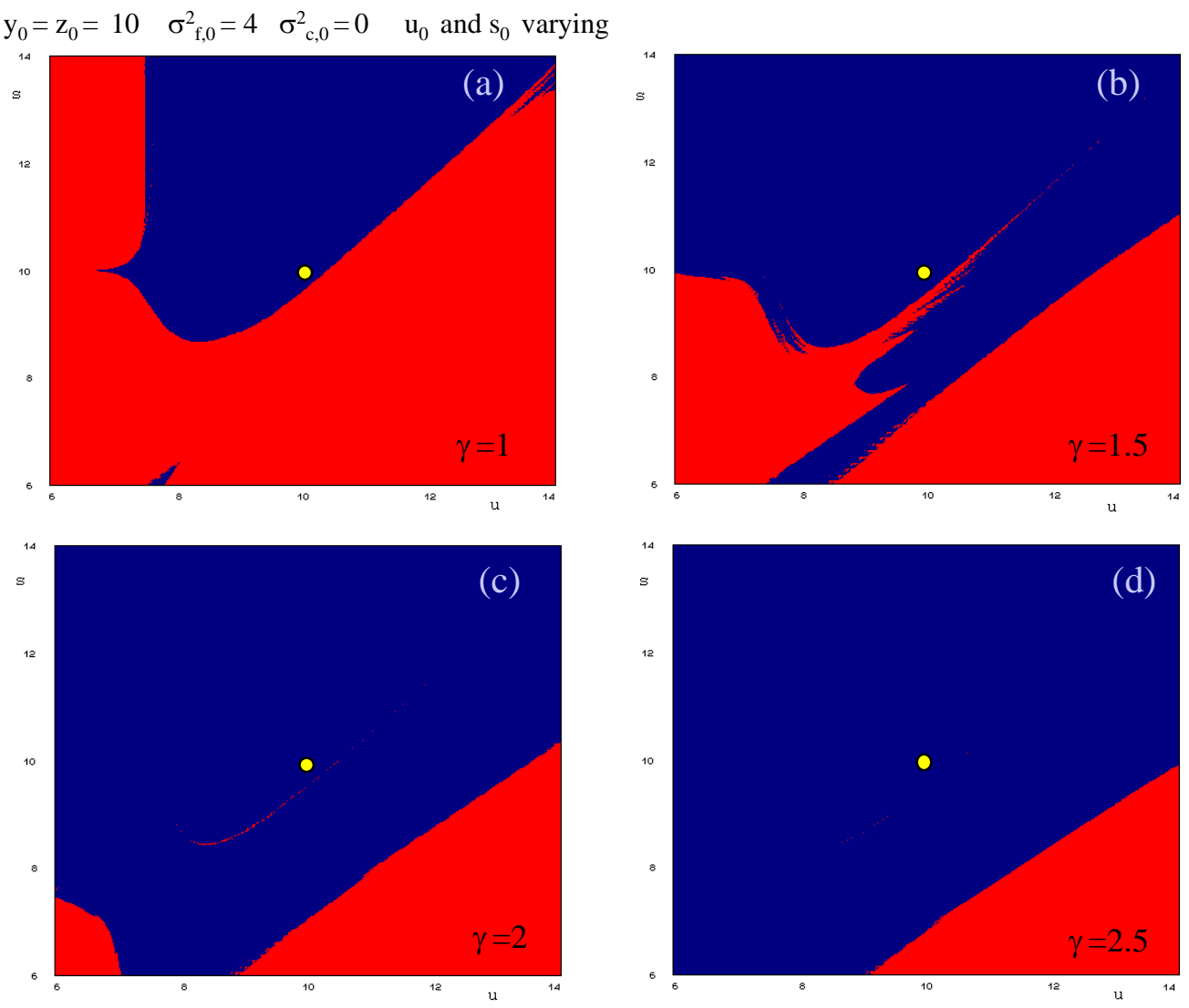

Figure 15: 
prevent the bubble from happening. The insight provided by Blanchard and Watson(1982) was to show that a bubble followed by a crash is possible in a stochastic rational expectations model. The crash occurs in such a model because agents attach some positive probability of a future crash. As a result, inevitably at some point a probable event becomes reality and a crash occurs. Agents, however, cannot predict when this will happen. The uncertainty about the exact time of the crash is necessary to make a "rational bubble" possible.

The problem with this "rational bubble" theory is that while it provides a sensible explanation of why bubbles can arise, it has no good explanation of why crashes occur ${ }^{31}$. The only reason why the latter occur is that they are assumed to occur. The assumption that crashes must occur sounds reasonable since whe have not observed an everlasting bubble. It is, however, imposed in an ad-hoc way, from outside the model ${ }^{32}$. In models where rational and irrational agents interact (DeLong, Shleifer, Summers and Waldmann(1990), Shleifer and Vishny(1997), and Abreu and Brunnermeier(2003)), bubbles arise because of a failure of arbitrage by the rational agents. These models also assume that crashes occur for exogenous reasons.

Another implication of the "rational bubble" model is that the exchange rate (asset price) is always on a bubble path. The reason is that the fundamental solution has a knife-edge property (saddle path). This means that the slightest deviation from the fundamental path brings the exchange rate on an unstable path. In a stochastic environment these slight deviations are inevitable. Thus the "rational bubble" theory predicts that the exchange rate will permanently be on a bubble path.

In our model a bubble is a locally stable equilibrium (a fixed point attractor) to which the exchange rate is attracted if exogenous shocks brings it in the basin of attraction of the bubble equilibrium. At the same time also the fundamental equilibrium is locally stable. This makes the "behavioural" bubble fundamentally different from the "rational bubble". First, in our behavioural model one needs a sufficiently large shock away form the fundamental to move the exchange rate towards a bubble attractor. Thus in "normal" times the exchange rate is driven by its fundamental value. This contrasts with the "rational bubble" theory in which the fundamental equilibrium is unstable, so that the exchange rate is always on an unstable bubble path. Second, the forces that lead to a bubble are the same as the forces that lead to a crash. We showed that large shocks

\footnotetext{
${ }^{31}$ The Blanchard-Watson rational bubble model can also be criticised for the fact that it predicts the occurrence of bubbles whose features are not found in empirical evidence. For example, it predicts that the bubbles are exponentially distributed, whereas the empirical evidence suggests that there are fat tails in the distribution of bubbles (see Mandelbrot(1997) and Lux and Sornette (2002)). In addition, the rational bubble model predicts that there is symmetry between bubble and crash phases, i.e. that after the crash the asset price returns to its fundamental value. Again, this does seem to square with the empirical evidence (see Sornette(2003)).

32 There is an important literature analysing the conditions under which rational bubbles occur in general equilibrium models. In general, the conditions for such bubbles to occur are tighter in these models than in partial equilibrium models because of some finiteness condition(e.g. a finite number of individuals, see Tirole(1982)). Typically these models have not been concerned with an explicit modelling of the crash.
} 
in the fundamental increase the probability of the occurrence of a bubble. Once in a bubble equilibrium a sufficiently large shock in the fundamental leads to a crash. In this sense our model provides for a theory of both the occurrence of a bubble and its subsequent crash. Third, the timing of the bubble and of the crash is uncertain. This uncertainty is not imposed exogenously but comes from the structure of the model. For we have shown that a bubble equilibrium of the underlying deterministic model is only locally stable, and in general it lies very close to the boundary of its basin of attraction; furthermore, the basins of attraction around the fundamental and the bubble equilibrium have often a fractal nature. As a result, the exact timing of the bubble and of the crash is dependent on "trivial events".

The view of a bubble as an equilibrium concept is reminiscent of the notion of "sunspots" which is also an equilibrium concept in rational expectations models (see Blanchard and Fischer(1989), p255, and Azariadis and Guesnerie(1984)). Sunspot equilibria arise because some agents believe that an arbitrary variable (sunspots) influences the asset price. As a result, rational agents who know this, attach some probability that a sunspot equilibrium will be reached. In our model a bubble equilibrium exists because some agents use extrapolative forecasting rules which under certain conditions can crowd out agents who believe in the existence of a fundamental value of the exchange rate. Thus, a bubble equilibrium is possible not because some agents are irrational and believe that sunspots affect the exchange rate, but because these agents are agnostic about the existence of fundamentals (including sunspots), and therefore rely only on the past exchange rate movements as the source of their information.

\section{Conclusion}

Up to now theoretical analysis of bubbles and crashes has been done almost exclusively in the context of models with perfectly and fully informed agents. This has led to the theory of "rational bubbles". In this paper we use an alternative framework in which agents are boundedly rational. We apply this framework to analyse the emergence and the subsequent disappearance of bubbles in the foreign exchange market. The analysis could easily be extended to other asset markets.

The special feature of our model is that individual agents recognize that they are not capable of understanding and processing the complex information structure of the underlying model. As a result, they use simple rules to forecast the exchange rates. These agents can be said to be boundedly rational That is, agents check the 'fitness' (profitability) of the forecasting rule at each point in time and decide to reject the rule if it is less profitable (in a risk adjusted sense) than competing rules. Our model is in the tradition of evolutionary dynamics where agents use trial and error strategies. We assume that some of the forecasting rules are based on extrapolating past exchange rate movements (technical trading) and others are based on mean reversion towards the fundamental rate (fundamentalism). 
The model generates two types of equilibria. The first one, which we called a fundamental equilibrium, is one in which the exchange rate converges to its fundamental value. The exchange rate, however, can also converge to a second type of equilibrium, which we called a non-fundamental (bubble) equilibrium, and which is reached in a self-fulfilling manner. An important feature of the bubble equilibrium is that technical traders (extrapolative forecasting) take over most of the market, so that fundamental influences on the exchange rate disappear. We simulated the model in a stochastic environment and generated complex scenarios of bubbles and crashes. One interesting aspect of the model is that it explains both the emergence of the bubble and its subsequent crash. That is, we found that the forces that trigger the emergence of a bubble are the same as those that lead to its collapse. This contrasts with the "rational bubble" model that has not found a satisfactory explanation for a crash to occur yet.

We also analysed under what conditions bubbles and crashes occur. We found that when agents react strongly to changing relative profitabilities of the different forecasting rules, the frequency of bubbles increases. Similarly, when technical analysts tend to extrapolate past movements of the exchange rate aggressively, the probability of bubbles and crashes increases. Finally, when agents are very risk averse bubbles will occur more frequently.

The theory of bubbles and crashes that we propose in this paper is different from the "rational bubble" theory. The difference exists at two levels. First, in our model bubbles are locally stable equilibria (fixed point attractors). These can be reached because certain shocks lead "fundamentalists" to be crowded out by technical traders in a self-fulfilling manner. One needs a sufficiently large shock in the fundamental variables, however, for this to happen. This contrasts with the "rational bubble" theory which defines a bubble as an explosive path of the asset price. Since the fundamental equilibrium path is unstable (knife-edge) the asset price will be permanently involved in an explosive bubble and crash dynamics in a stochastic rational expectations model.

Our bubble equilibria are also different from sunspot equilibria which arise in models where some (irrational) agents give importance to some arbitrary variables (sunspots) in the determination of the asset price. In contrast to these sunspot equilibria, our bubble equilibria arise because sometimes the market is dominated by agents who are agnostic about the fundamental variables that drive the asset price. 


\section{References}

Abreu, D. and Brunnermeier, M., 2003, Bubbles and Crashes, Econometrica, 71(1), 173-204.

Anderson, S., de Palma, A., Thisse, J.-F., 1992, Discrete Choice Theory of Product Differentiation, MIT Press, Cambridge, Mass.

Azariadis, C., and Guesnerie, R., 1984, Sunspots and Cycles, CARESS Working Paper 83-22R, University of Pennsylvania, March

Bacchetta, P. and van Wincoop E., 2003, Can information heterogeneity explain the exchange rate determination puzzle?, NBER working paper 9498.

Baxter, M., Stockman, 1989, A., "Business Cycles and the Exchange Rate Regime. Some International Evidence", Journal of Monetary Economics, 23, may 377-400.

Bischi, G.I., Gardini, L. and Mira, C., 1999, Plane maps with denominator I. Some generic properties, International Journal of Bifurcation and Chaos, 9(1), 119-153.

Blanchard ,O.J., 1979, " Speculative bubbles, crashes and rational expectations", Economics Letters, 3, 387-389.

Blanchard, O.J., and Fischer, S., 1989, Lectures on Macroeconomics, MIT press.

Blanchard, O.J., and Watson, M.W., 1982, "Bubbles, rational expectations and speculative markets", in Wachtel, P., eds., Crisis in economic and financial stucture: bubbles, bursts, and shocks. Lexington books: Lexington.

Brock, W., and Hommes, C., 1997, A Rational Route to Randomness, Econometrica, 65, 1059-1095

Brock, W., and Hommes, C.,1998, Heterogeneous beliefs and routes to chaos in a simple asset pricing model, Journal of Economic Dynamics and Control, $22,1235-1274$.

Brunnermeier, M., 2001, Asset pricing under asymmetric information: bubbles, crashes technical analysis and herding, Oxford University Press.

Cheung, Y., and Chinn, M., (1989), Macroeconomic Implications of the Beliefs and Behavior of Foreign Exchange Traders, mimeo, University of California, Santa Cruz.

Cheung, Y., Chinn, M., and Marsh, (1999), How Do UK-Based Foreign Exchange Dealers Think Their Markets Operates?, CEPR Discussion Paper, no. 2230

Chiarella, C., Dieci, R., Gardini, 2002, L., "Speculative behaviour and complex asset price dynamics", Journal of Economic Behaviour and Organisation.

Copeland, L., 2000, Exchange Rates and International Finance, 3rd ed., Prentice Hall.

De Grauwe, P. , Dewachter, H., and Embrechts, 1993, M., Exchange Rate Theories. Chaotic Models of the Foreign Exchange Markets, Blackwell.

De Grauwe, P., and Grimaldi, M., Exchange Rate Puzzles. 2003, A Tale of Switching Attractors, paper presented at the EEA Meeting, Stockholm, 2003

de Vries, C., 2000, "Fat tails and the history of the guilder", Tinbergen Magazine, 4, Fall, pp. 3-6. 
De Long, J., Bradford, B., Schleiffer and Summers, L., 1990, "Noise Trader Risk in Financial Markets", Journal of Political Economy.

Dornbusch R., 1976, "Expectations and exchange rate dynamics", Journal of Political Economy 84.

Engel C. and Morley J., 2001, "The adjustment of prices and the adjustment of the exchange rate", Discussion paper, Department of Economics, University of Wisconsin.

Evans, M., and Lyons, R., 1999, "Order Flow and Exchange Rate Dynamics", NBER Working Paper, no. 7317.

Evans, G., and Honkapohja, S., 2001, Learning and Expectations in Macroeconomics, Princeton University Press.

Faust, J., Rogers, J., Swanson, E., and Wright, J., 2002, dentifying the Effects of Monetary Policy Shocks on Exchange Rates Using High Frequency Data, International Finance Discussion Papers, no. 739, Board of Governors of the Federal Reserve System, Washington, D.C.

Flood, R, and Rose, A., 1995, "Fixing the Exchange Rate Regime: A virtual Quest for Fundamentals", Journal of Monetary Economics, 36, August, 3-37.

Frankel, J., and Froot, K., 1987, "Understanding the US Dollar in the Eighties: The Expectations of Fundamentalists and Chartists", Economic Record.

Garber,P.M., 2000, "Famous first bubbles", MIT press.

Goodhart, C., 1989, "News and the Foreign Exchange Market", LSE Financial Markets Group Discussion paper, 71.

Goodhart, C., and Figliuoli, L., 1991, "Every Minute Counts in the Foreign Exchange Markets", Journal of International Money and Finance, 10, 23-52.

Guillaume D., 1996 "Chaos, randomness and order in the foreign exchange markets" PhD Thesis K.U.Leuven

Huisman, R., Koedijk, K., Kool, C., and Palm, F., 2002, The tail-fatness of FX returns reconsidered, in De Economist, 150, no. 3, September, 299-312.

Isard, P., 1995, Exchange Rate Economics, Cambridge University Press.

Johansen,A., Sornette,D., 1999, Modeling the stock market prior to large crashes, The European Physical Journal B, 9, 167-174.

Kahneman, D., Knetsch, J., and Thaler, R., 1991, The endowment effect, loss aversion and status quo bias, Journal of Economic Perspectives, 5, 193-206.

Kahneman, D., 2002, Maps of Bounded Rationality: A Perspective on Intuitive Judgment and Choice, Nobel Prize Lecture, December 8, Stockholm.

Kandel,E. and Pearson, N.D., 1995, "Differential interpretation of public signals and trade in speculative markets", Journal of political Economy, 4, 831872 .

Kindleberger, C,. Manias, Panics, and Crashes. A History of Financial Crises. 1978, John Wiley \& Sons, New York, 263 pages.

Kurz, M., 1994, "On the Structure and Diversity of Rational Beliefs", Economic Theory, 4, 877-900.

Kurz, M., and Motolese, M., 2001, "Endogenous Uncertainty and Market Volatility", Economic Theory, 16, 497-544.

Lui, Y., and Mole, D., The Use of Fundamental and Technical Analyses by Foreign Exchange Dealers: Hong Kong Evidence, Journal of International 
Money and Finance, 17, pp. 535-45

Lux T., 1998, "The socio-economic dynamics of speculative markets: interacting agents, chaos, and fat tails of return distributions", Journal of Economic Behaviour and Organisation, vol.33.

Lux T., Marchesi M., 2000, "Volatility clustering in financial markets: a microsimulation of interacting agents", International Journal of Theoretical and Applied Finance.

Lux T., Sornette D., 2002, "On rational bubbles and fat tails", Journal of Money, Credit and Banking, 34, No 3, pp 589-610.

Lyons, R., 2001, The Microstructure Approach to Exchange Rates, MIT Press, Cambridge, Mass.

Mandelbrot, B., 1963, The variation of certain speculative prices, The Journal of Business, University of Chicago, 36, 394-419.

Mandelbrot, B., 1997, Fractals and Scaling in Finance, Springer Verlag, 551 pages.

Meese, R., and Rogoff, 1983, "Empirical Exchange Rate Models of the Seventies: Do they Fit Out of Sample?", Journal of International Economics, 14, 3-24.

Mentkhoff, L., (1997), Examining the Use of Technical Currency Analysis, International Journal of Finance and Economics, 2, pp. 307-18

Mentkhoff, L., (1998), The Noise Trading Approach - Questionnaire Evidence from Foreign Exchange, Journal of International Money and Finance, 17, pp. $547-64$.

Obstfeld, M. and Rogoff, K., 1996, Foundations of International Macroeconomics, MIT Press, Cambridge, Mass.

Shiller, R., 2000, Irrational Exuberance, Princeton University Press,

Schittenkopf C., Dorffner G., Dockner E.,2001, "On nonlinear, stochastic dynamics in economics and financial time series", Studies in Nonlinear Dynamics and Econometrics 4(3), pp. 101-121.

Shleifer, A. and Vishny, R., 1997, The Limits to Arbitrage, Journal of Finance, $52(1), 35-55$.

Shleifer, A., 2000, Introduction to Behavioural Finance, Clarendon Press.

Simon, H., 1955, A Behavioral Model of Rational Choice, The Quarterly Journal of Economics, vol. 69, no. 1, 99-118.

Sornette, D., 2003, Why Stock Markets Crash, Princeton University Press.

Taylor, M., and Allen, H., 1992, "The Use of Technical Analysis in the Foreign Exchange Market", Journal of International Money and Finance, 11, 304-14.

Thaler, R., 1994, Quasi Rational Economics, Russell Sage Foundation, New York.

Tirole, J., 1982, On the Possibility of Speculation under Rational Expectations, Econometrica, 50, 1163-1181.

Tversky, A., and Kahneman, D., (1981), The framing of decisions and the psychology of choice, Science, 211, 453-458.

Wei Shang-Jin and Kim Jungshik 1997. "The big players in the foreign exchange market:do they trade on information or noise?". NBER working paper 
6256.

\section{A Appendix 1: The variance ratio $\sigma_{f, t}^{2} / \sigma_{c, t}^{2}$ at the steady state}

In this appendix we show the ratio of the variance of the fundamentalist and chartists $\sigma_{f, t}^{2}$ and $\sigma_{c, t}^{2}$ as it converges to its steady state value. We simulated the model for different parameter configurations and different initial values of the exchange rate. In each case we found that the variance ratio converged to 1 as the system approached the steady state.

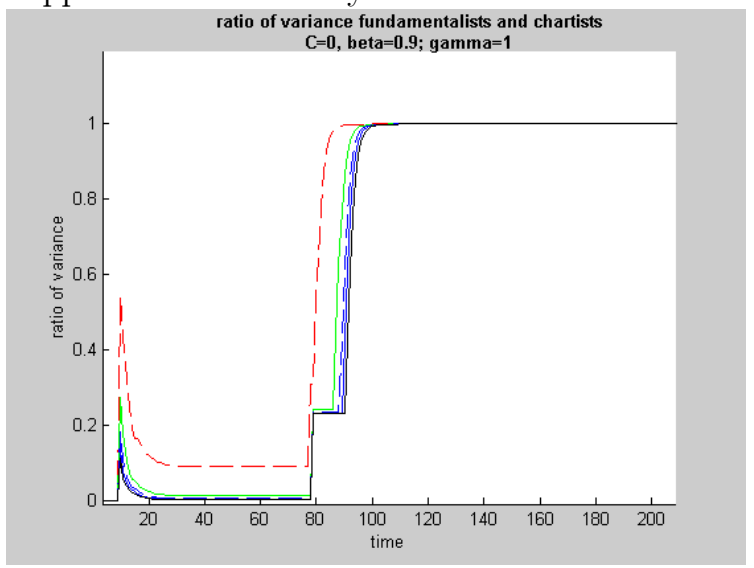




\section{B Appendix 2 : Numerical values of the para- meters used in the base simulation}

In the following table we present the numerical values of the model. In the first column we listed the parameters of the model, in the second column we present the numerical values in the base simulations. The last column indicates whether or not we have performed a sensitivity analysis on these numerical values. If not, we use the same numerical value in all simulations.

Table 1: Numerical values of parameters

\begin{tabular}{|c|c|c|}
\hline Parameters & values & sensitivity analysis \\
\hline$\psi$ & 0.2 & No \\
$\rho$ & 0.6 & No \\
$\beta$ & 0.8 & Yes \\
$\theta$ & 0.6 & No \\
$\gamma$ & 1 & Yes \\
$\mu$ & 1 & Yes \\
$H=K$ (lags) & 5 & No \\
$r$ and $r^{*}$ & 0 & No \\
\hline
\end{tabular}




\title{
CESifo Working Paper Series
}

\author{
(for full list see www.cesifo.de)
}

1366 Harry Grubert, Tax Credits, Source Rules, Trade and Electronic Commerce: Behavioral Margins and the Design of International Tax Systems, December 2004

1367 Hans-Werner Sinn, EU Enlargement, Migration and the New Constitution, December 2004

1368 Josef Falkinger, Noncooperative Support of Public Norm Enforcement in Large Societies, December 2004

1369 Panu Poutvaara, Public Education in an Integrated Europe: Studying to Migrate and Teaching to Stay?, December 2004

1370 András Simonovits, Designing Benefit Rules for Flexible Retirement with or without Redistribution, December 2004

1371 Antonis Adam, Macroeconomic Effects of Social Security Privatization in a Small Unionized Economy, December 2004

1372 Andrew Hughes Hallett, Post-Thatcher Fiscal Strategies in the U.K.: An Interpretation, December 2004

1373 Hendrik Hakenes and Martin Peitz, Umbrella Branding and the Provision of Quality, December 2004

1374 Sascha O. Becker, Karolina Ekholm, Robert Jäckle and Marc-Andreas Mündler, Location Choice and Employment Decisions: A Comparison of German and Swedish Multinationals, January 2005

1375 Christian Gollier, The Consumption-Based Determinants of the Term Structure of Discount Rates, January 2005

1376 Giovanni Di Bartolomeo, Jacob Engwerda, Joseph Plasmans, Bas van Aarle and Tomasz Michalak, Macroeconomic Stabilization Policies in the EMU: Spillovers, Asymmetries, and Institutions, January 2005

1377 Luis H. R. Alvarez and Erkki Koskela, Progressive Taxation and Irreversible Investment under Uncertainty, January 2005

1378 Theodore C. Bergstrom and John L. Hartman, Demographics and the Political Sustainability of Pay-as-you-go Social Security, January 2005

1379 Bruno S. Frey and Margit Osterloh, Yes, Managers Should Be Paid Like Bureaucrats, January 2005 
1380 Oliver Hülsewig, Eric Mayer and Timo Wollmershäuser, Bank Loan Supply and Monetary Policy Transmission in Germany: An Assessment Based on Matching Impulse Responses, January 2005

1381 Alessandro Balestrino and Umberto Galmarini, On the Redistributive Properties of Presumptive Taxation, January 2005

1382 Christian Gollier, Optimal Illusions and Decisions under Risk, January 2005

1383 Daniel Mejía and Marc St-Pierre, Unequal Opportunities and Human Capital Formation, January 2005

1384 Luis H. R. Alvarez and Erkki Koskela, Optimal Harvesting under Resource Stock and Price Uncertainty, January 2005

1385 Ruslan Lukach, Peter M. Kort and Joseph Plasmans, Optimal R\&D Investment Strategies with Quantity Competition under the Threat of Superior Entry, January 2005

1386 Alfred Greiner, Uwe Koeller and Willi Semmler, Testing Sustainability of German Fiscal Policy. Evidence for the Period 1960 - 2003, January 2005

1387 Gebhard Kirchgässner and Tobias Schulz, Expected Closeness or Mobilisation: Why Do Voters Go to the Polls? Empirical Results for Switzerland, 1981 - 1999, January 2005

1388 Emanuele Bacchiocchi and Alessandro Missale, Managing Debt Stability, January 2005

1389 Assar Lindbeck and Dirk Niepelt, Improving the SGP: Taxes and Delegation rather than Fines, January 2005

1390 James J. Heckman and Dimitriy V. Masterov, Skill Policies for Scotland, January 2005

1391 Emma Galli \& Fabio Padovano, Sustainability and Determinants of Italian Public Deficits before and after Maastricht, January 2005

1392 Angel de la Fuente and Juan Francisco Jimeno, The Private and Fiscal Returns to Schooling and the Effect of Public Policies on Private Incentives to Invest in Education: A General Framework and Some Results for the EU, January 2005

1393 Juan C. Conesa and Carlos Garriga, Optimal Response to a Demographic Shock, January 2005

1394 Christian Gollier, Optimal Portfolio Management for Individual Pension Plans, February 2005

1395 Ruslan Lukach, Joseph Plasmans and Peter M. Kort, Innovation Strategies in a Competitive Dynamic Setting, February 2005

1396 Gebhard Kirchgässner, (Why) Are Economists Different?, February 2005 
1397 Marko Köthenbürger, Panu Poutvaara and Paola Profeta, Why are More Redistributive Social Security Systems Smaller? A Median Voter Approach, February 2005

1398 Gabrielle Demange, Free Choice of Unfunded Systems: A First Assessment, February 2005

1399 Carlos Fonseca Marinheiro, Sustainability of Portuguese Fiscal Policy in Historical Perspective, February 2005

1400 Roel M. W. J. Beetsma and Koen Vermeylen, The Effect of Monetary Unification on Public Debt and its Real Return, February 2005

1401 Frank Asche, Petter Osmundsen and Maria Sandsmark, Is It All Oil?, February 2005

1402 Giacomo Corneo, Media Capture in a Democracy: The Role of Wealth Concentration, February 2005

1403 A. Lans Bovenberg and Thijs Knaap, Ageing, Funded Pensions and the Dutch Economy, February 2005

1404 Thiess Büttner, The Incentive Effect of Fiscal Equalization Transfers on Tax Policy, February 2005

1405 Luisa Fuster, Ayşe İmrohoroğlu and Selahattin İmrohoroğlu, Personal Security Accounts and Mandatory Annuitization in a Dynastic Framework, February 2005

1406 Peter Claeys, Policy Mix and Debt Sustainability: Evidence from Fiscal Policy Rules, February 2005

1407 James M. Malcomson, Supplier Discretion over Provision: Theory and an Application to Medical Care, February 2005

1408 Thorvaldur Gylfason, Interview with Assar Lindbeck, February 2005

1409 Christian Gollier, Some Aspects of the Economics of Catastrophe Risk Insurance, February 2005

1410 Gebhard Kirchgässner, The Weak Rationality Principle in Economics, February 2005

1411 Carlos José Fonseca Marinheiro, Has the Stability and Growth Pact Stabilised? Evidence from a Panel of 12 European Countries and Some Implications for the Reform of the Pact, February 2005

1412 Petter Osmundsen, Frank Asche, Bård Misund and Klaus Mohn, Valuation of International Oil Companies -The RoACE Era, February 2005

1413 Gil S. Epstein and Shmuel Nitzan, Lobbying and Compromise, February 2005

1414 Marcel F. M. Canoy, Jan C. van Ours and Frederick van der Ploeg, The Economics of Books, February 2005 
1415 Eric A. Hanushek and Ludger Wößmann, Does Educational Tracking Affect Performance and Inequality? Differences-in-Differences Evidence across Countries, February 2005

1416 George Kapetanios and M. Hashem Pesaran, Alternative Approaches to Estimation and Inference in Large Multifactor Panels: Small Sample Results with an Application to Modelling of Asset Returns, February 2005

1417 Samuel Mühlemann, Jürg Schweri, Rainer Winkelmann and Stefan C. Wolter, A Structural Model of Demand for Apprentices. February 2005

1418 Giorgio Brunello and Lorenzo Rocco, Educational Standards in Private and Public Schools, February 2005

1419 Alex Bryson, Lorenzo Cappellari and Claudio Lucifora, Why so Unhappy? The Effects of Unionisation on Job Satisfaction, March 2005

1420 Annalisa Luporini, Relative Performance Evaluation in a Multi-Plant Firm, March 2005

1421 Giorgio Bellettini and Carlotta Berti Ceroni, When the Union Hurts the Workers: A Positive Analysis of Immigration Policy, March 2005

1422 Pieter Gautier, Michael Svarer and Coen Teulings, Marriage and the City, March 2005

1423 Ingrid Ott and Stephen J. Turnovsky, Excludable and Non-Excludable Public Inputs: Consequences for Economic Growth, March 2005

1424 Frederick van der Ploeg, Back to Keynes?, March 2005

1425 Stephane Dees, Filippo di Mauro, M. Hashem Pesaran and L. Vanessa Smith, Exploring the International Linkages of the Euro Area: a Global VAR Analysis, March 2005

1426 Hans Pitlik, Friedrich Schneider and Harald Strotmann, Legislative Malapportionment and the Politicization of Germany's Intergovernmental Transfer System, March 2005

1427 Konstantinos Angelopoulos and Apostolis Philippopoulos, The Role of Government in Anti-Social Redistributive Activities, March 2005

1428 Ansgar Belke and Daniel Gros, Asymmetries in the Trans-Atlantic Monetary Policy Relationship: Does the ECB follow the Fed?, March 2005

1429 Sören Blomquist and Luca Micheletto, Optimal Redistributive Taxation when Government's and Agents' Preferences Differ, March 2005

1430 Olof Åslund and Peter Fredriksson, Ethnic Enclaves and Welfare Cultures - QuasiExperimental Evidence, March 2005

1431 Paul De Grauwe, Roberto Dieci and Marianna Grimaldi, Fundamental and NonFundamental Equilibria in the Foreign Exchange Market. A Behavioural Finance Framework, March 2005 